\title{
The Impact of Mobility Models on Geographic Routing in Multi-Hop Wireless Networks and Extensions - A Survey
}

\author{
T. Sakthivel \\ Firstsoft Technologies Private Limited, Chennai, Tamil Nadu, India \\ sakthi@firstsoftech.com \\ Allam Balaram \\ Department of Information Technology, MLR Institute of Technology, Hyderabad, Telangana, India \\ balaramallam@gmail.com
}

Received: 03 September 2021 / Revised: 27 September 2021 / Accepted: 01 October 2021 / Published: 27 October 2021

\begin{abstract}
Multi-hop Wireless Networks (MWNs) emerge as an enabling communication technology, evolving rapidly due to the accelerating advancements and creating potential network applications that significantly improve the quality of life. Pure general-purpose MANET laid the theoretical foundation for MWNs, and many extensions are successfully deployed in commercial networks. This article surveys geographical routing protocols and mobility models applicable to MWNs and their recently proposed extensions. Mobility is a significant factor that profoundly impacts the performance of multi-hop geographical routing. This study analyzes various mobility models that significantly influence the performance of geographical routing protocols based on the characteristics and behavior of various network extensions. This survey investigates the primary challenges in designing geographical routing for various mobility models that notably impact the routing performance for a particular network extension. It also explores the enormous potential of geographical routing protocols under each extension and adequately addressing the routing and mobility-related issues. The essential factors that impact geographical routing, the freshness of location information, and the adaptive location update are examined extensively for various network extensions. Finally, the survey concludes with future research challenges and directions.
\end{abstract}

Index Terms - Multihop Wireless Networks, Geographical Routing, Mobility Models, MANET, FANET, WSN, VANET, DTN.

\section{INTRODUCTION}

Due to the rapid technological advancement of computing and communication, Multi-hop Wireless Networks (MWNs) have recently emerged as popular network platforms and received a great deal of attention in research. In MWNs, the wireless nodes form a dynamic network with the support of a shared wireless medium, with or without any infrastructure. Multihop routing has become an essential component due to the short communication range of mobile nodes. Thus, the intermediate nodes act as routers to enable hop-by-hop data transmission between the source and destination cooperatively. MANET is the theoretical foundation of many recent network extensions, and the extensive research activities notably expand the capabilities of wireless networks that lead to potential applications [1].

This massive expansion significantly contributed to the development of novel solutions in real multi-hop network environments. This survey mainly concentrates on geographical routing [2] and its mobility issues in prominent MWN extensions such as MANET [3], Flying Ad-hoc NETworks (FANETs) [4], Wireless Sensor Network (WSN) [5], Delay-Tolerant Network [DTN] [6], Vehicular Ad-hoc NETwork (VANET) [7] [8] and these networks that evolved significantly due to its emerging applications and recent research attentions. The geographical routing can deliver packets efficiently to overcome the scalability and mobility issues in MWNs [9].

Geographic routing reduces delay and substantial routing overhead when large networks operate with highly dynamic mobility. Geographical routing eliminates the use of expensive control packets and enables only the next-hop link towards the destination. If the source knows the destination location, a network-wide search by sending the control packets is eliminated. The geographical routing forwards data packets based on the physical location of nodes and enables an efficient context-aware routing. To decide the next hop, each node must trace the physical location of neighbors, and thus it requires efficient location service and location update scheme. The distance is estimated between the mobile nodes by utilizing the signal strength of the received packet or time delays in direct communication. However, the geographic 


\section{SURVEY ARTICLE}

routing needs to update the location information frequently depends on the node mobility, in turn, high mobility increases the rate of a location update.

Node mobility is an essential characteristic of MWNs that significantly impacts multihop routing protocols [10]. Mobility induces frequent path breakages in multihop that lead to increasing the overhead and delay. Thus, multihop routing has to adapt to the mobility pattern of nodes to deliver the performance. Mobility models are designed to support mobility traces collected from humans, wild animals, vehicles, and other real-world objects. As mobility has become an integral part of the wireless network, a broad range of mobility models have been developed recently to capture the realistic mobility of objects depending on the applications. As everything is moving in real environments, mobility is a crucial concept in the wireless networks that describe the reality of node mobility. Although the geographical protocol does not store the network topology information, the nodes must still know where one-hop neighbor nodes are placed.

The negative impact of node mobility is significantly high on the maintenance of accurate neighbor lists. In geographical routing, location information is paramount for routing decisions, and the accuracy of location information has a massive impact on routing performance. Location error or inaccuracy is often combined with the problems caused by the unpredictable mobility of nodes [11]. Node mobility is considered as the primary factor in the location update scheme, and it degrades the probability of accuracy of the neighbor node discovery process.

The essential factors that impact the geographical routing are the freshness of location information and the adaptive location update scheme with the characteristics of node mobility models. The mobility model provides mobility patterns based on the position of node, direction, and speed over a specific period to specify the characteristics of nodes in an active network environment [12]. The inaccurate location information due to the random node mobility and its pattern decreases the geographic routing performance.

The time gap between the location update beaconing is larger than employing the location information for packet routing. It increases the importance of the characterization of node mobility and its models with geographic routing. Recently, the design of the location update scheme has considered the mobility parameters such as speed, direction, prediction, and time for observing node location and improves the performance. Thus, designing a new mobility adaptive location service with minimum overhead is essential. It is clear that the efficiency of the geographical routing purely depends on the accuracy of location update that relies on the node mobility and their pattern.
1.1. Challenges Related to Mobility in Multi-hop Wireless Networks

The efficiency of MWN is affected in different ways by mobility. The mobility models developed for MWN have some common shortcomings [11][12]. These are listed as follows.

- The rapid advancement of ICT enables mobility and mobile devices as an inevitable part of life. Developing a mobility model that mimics the real mobile object movement is a significant challenge while testing the protocols using the simulators. It is also challenging to generalize real-time applications from small-scale simulations. Other factors are an irregular movement of the human that creates a significant challenge in movement prediction and a lack of migration of wireless devices out of a modeled area as the movement of humans cannot be restricted in real-time.

- Only a few mobility models consider the obstacles in the simulation. However, in the real world, there are hills, buildings, and trees. However, modeling obstacles only by restricting the communication range is not enough to reflect reality since the mobile devices should be restricted to move towards the coordinates of an obstacle. The mobile device coverage is not in regular shape, i.e., a circle. However, in simulation, the communication range of a wireless device is taken as circular.

- In the design of the mobility model, poor location prediction accuracy results in the absence of user behavior, community structure, social relationships, and the correlation between user movement.

- Validating the mobility models is crucial to ensure the applicability of the model to different types of networks. However, it is difficult due to the impracticability of collecting actual mobility data.

Traditional geographic routing protocols assume that the performance obtained from the simulation is equal to the realtime. Table1 lists the challenges when applying geographic routing in different environments.

Mobility modeling plays a crucial role in evaluating the performance of geographic routing protocols over MWNs. The gap between the mobility models in a simulation environment and real-time applications impacts geographical routing protocols.

\subsection{Simulator Support for Mobility Models in Multi-Hop Wireless Networks}

Geographical routing protocols are designed for various application scenarios. The untested new protocols cannot be installed on a large-scale network due to the uncertainty of its performance. They need to be tested with analytical modeling 


\section{SURVEY ARTICLE}

or simulation tools [13]. Analytical modeling faces significant limitations since the deduced results are not precise in terms of the resources consumed. In contrast, affordable simulation tools provide precise results and accurately evaluate the proposed protocols. Simulation allows the designer to get practical feedback, validate the correctness and efficiency of complex protocols at an affordable testing cost within a short period. The designer can understand the behavior and the complexity of the protocol by applying a different abstraction level. Table 2 lists some of the network simulators and their mobility models.

\begin{tabular}{|c|c|c|c|}
\hline \multirow[t]{2}{*}{ Network } & \multirow{2}{*}{$\begin{array}{l}\text { Movement } \\
\text { Pattern }\end{array}$} & \multicolumn{2}{|c|}{ Mobility Aspects Impacting Geographic Routing Efficiency } \\
\hline & & In Simulation & In Real Time \\
\hline \multirow[t]{3}{*}{ MANET } & Random & $\begin{array}{l}\text { 1) Location inaccuracy due to failure } \\
\text { of location prediction during } \\
\text { mobility } \\
\text { 2) Location prediction failure, when the } \\
\text { device follows the completely } \\
\text { random movement } \\
\text { 3) Locating the mobile destination } \\
\text { 4) Local maximum Problem }\end{array}$ & $\begin{array}{l}\text { 1) The mobile nodes located in a real-time } \\
\text { MANET environment is predictable and } \\
\text { not completely random } \\
\text { 2) The continuous movement of devices } \\
\text { results in the unavailability of the router, } \\
\text { i.e., local maximum }\end{array}$ \\
\hline & Community & $\begin{array}{l}\text { 1) Lack of social context and its } \\
\text { associated group reforming leads to } \\
\text { reduced accuracy in prediction } \\
\text { 2) Restricted traveling Distance within a } \\
\text { modeled area }\end{array}$ & $\begin{array}{l}\text { 1) Unrestricted distance to travel } \\
\text { 2) Dynamic formation of community }\end{array}$ \\
\hline & $\begin{array}{l}\text { Simple } \\
\text { Human }\end{array}$ & $\begin{array}{l}\text { 1) Lack of using the advantage of spatial } \\
\text { regularity in human mobility } \\
\text { 2) Lack of modeling obstacles during } \\
\text { mobility }\end{array}$ & $\begin{array}{l}\text { 1) Some nodes meet on a random basis, but } \\
\text { some nodes are more frequently and } \\
\text { regularly } \\
\text { 2) Periodical reappearance at a preferred } \\
\text { location } \\
\text { 3) Human movement through obstacles is } \\
\text { not possible }\end{array}$ \\
\hline \multirow[t]{2}{*}{ VANET } & Traffic & $\begin{array}{l}\text { 1) Link availability based intersection } \\
\text { selection in routing is affected by the } \\
\text { collision } \\
\text { 2) Lack of linking driver decision and } \\
\text { movement prediction }\end{array}$ & $\begin{array}{l}\text { 1) Modeling obstacles in real-time are } \\
\text { difficult } \\
\text { 2) The dynamic driver decision may not } \\
\text { always assure the link availability } \\
\text { 3) Lack of RSUs in real road scenario }\end{array}$ \\
\hline & Behavioral & $\begin{array}{l}\text { 1) Lack of considering the driver decision } \\
\text { and speed acceleration together } \\
\text { 2) Vehicles random movement on the road } \\
\text { increases the frequent beaconing resulting } \\
\text { in a collision }\end{array}$ & $\begin{array}{l}\text { 1) Vehicle distribution is not entirely } \\
\text { random } \\
\text { 2) Lack of RSU availability in real road } \\
\text { scenario }\end{array}$ \\
\hline \multirow{2}{*}{ WSN } & Controlled & $\begin{array}{l}\text { 1) No hot spot issue } \\
\text { 2) Energy hole only due to the usage in } \\
\text { routing }\end{array}$ & $\begin{array}{l}\text { 1) Sensor damage by animals or natural } \\
\text { disasters } \\
\text { 2) Path changes due to obstacles }\end{array}$ \\
\hline & $\begin{array}{l}\text { Non- } \\
\text { Controllable }\end{array}$ & $\begin{array}{l}\text { 1) Frequent location error due to mobility } \\
\text { reduces the accuracy } \\
\text { 2) Sensor movement in the modeled area } \\
\text { 3) A high energy consumption }\end{array}$ & $\begin{array}{l}\text { 1) The sensor movement cannot be } \\
\text { predefined } \\
\text { 2) Node mobility reduces the possibility of } \\
\text { local maximum and hot spot issues } \\
\text { 3) Sensor damage by animals or natural } \\
\text { disasters } \\
\text { 4) Path change due to obstacles }\end{array}$ \\
\hline
\end{tabular}

Table 1 Challenges in Modeling the Geographical Routing in Simulation and Real-Time 


\section{SURVEY ARTICLE}

\begin{tabular}{|c|c|c|c|c|c|}
\hline Tool & Type & Mobility Models & Language & Opportunities & $\begin{array}{l}\text { Network to } \\
\text { Model }\end{array}$ \\
\hline BonnMotion & \multirow[t]{2}{*}{$\begin{array}{l}\text { Mobility } \\
\text { Generator }\end{array}$} & \begin{tabular}{l}
\multicolumn{2}{l}{ Random WayPoint, } \\
Random \\
Manhattan \\
Gauss-Markov model, \\
and Reference \\
Group Mobility
\end{tabular} & Java & $\begin{array}{l}\text { Supporting } \\
\text { visualization tool }\end{array}$ & $\begin{array}{l}\text { MANET, } \\
\text { FANET, } \\
\text { WSN, and } \\
\text { VANETs }\end{array}$ \\
\hline MobiSim & & $\begin{array}{l}\text { Random WayPoint, } \\
\text { Random Walk, } \\
\text { Random Direction, } \\
\text { Manhattan Grid, } \\
\text { Gauss-Markov model, } \\
\text { Nomadic Community, } \\
\text { and Pursue }\end{array}$ & Java & $\begin{array}{ll}\text { Modeling } & \text { traffic } \\
\text { signs and } & \text { traffic } \\
\text { lights } & \end{array}$ & $\begin{array}{l}\text { MANET, } \\
\text { FANET, } \\
\text { WSN, and } \\
\text { VANETs }\end{array}$ \\
\hline NS2 & \multirow{7}{*}{$\begin{array}{l}\text { Network } \\
\text { Simulator }\end{array}$} & $\begin{array}{l}\text { Random WayPoint, } \\
\text { Random Walk, } \\
\text { Manhattan Grid, } \\
\text { Gauss-Markov model, } \\
\text { and Reference Point } \\
\text { Group Mobility } \\
\end{array}$ & $\begin{array}{l}\text { C++ and } \\
\text { OTCL }\end{array}$ & $\begin{array}{l}\text { Visualization is } \\
\text { an available and } \\
\text { very popular } \\
\text { simulator }\end{array}$ & $\begin{array}{l}\text { MANET, } \\
\text { FANET, } \\
\text { WSN, and } \\
\text { VANETs }\end{array}$ \\
\hline NS3 & & $\begin{array}{l}\text { Random WayPoint, } \\
\text { Random Walk, } \\
\text { Manhattan Grid, } \\
\text { Random Direction, } \\
\text { Gauss-Markov model, } \\
\text { and Reference Point } \\
\text { Group Mobility }\end{array}$ & $\begin{array}{l}\text { C++ and } \\
\text { Optional } \\
\text { Python } \\
\text { Bindings }\end{array}$ & $\begin{array}{l}\text { It supports TCP, } \\
\text { UDP, ICMP, } \\
\text { IPv4, multicast } \\
\text { routing protocols, } \\
\text { and CSMA } \\
\text { protocols. }\end{array}$ & $\begin{array}{l}\text { MANET, } \\
\text { FANET, } \\
\text { WSN, and } \\
\text { VANETs }\end{array}$ \\
\hline Omnet++ & & Random WayPoint & $\mathrm{C}++$ & $\begin{array}{l}\text { Supports a } \\
\text { graphical network } \\
\text { editor }\end{array}$ & $\begin{array}{l}\text { MANET, } \\
\text { FANET, } \\
\text { WSN, and } \\
\text { VANETs }\end{array}$ \\
\hline OPNET & & $\begin{array}{l}\text { Random WayPoint, } \\
\text { Random Walk, Random } \\
\text { Direction, and Group } \\
\text { Mobility }\end{array}$ & $\mathrm{C}$ and $\mathrm{C}++$ & $\begin{array}{l}\text { Supports very } \\
\text { large-scale } \\
\text { multihop wireless } \\
\text { Networks }\end{array}$ & $\begin{array}{l}\text { MANET, } \\
\text { FANET, } \\
\text { WSN, and } \\
\text { VANETs }\end{array}$ \\
\hline NetSim & & $\begin{array}{l}\text { Random Walk and } \\
\text { Random WayPoint }\end{array}$ & $\mathrm{C}$ and Java & $\begin{array}{l}\text { It provides a GUI } \\
\text { with the features } \\
\text { of drag and drops } \\
\text { functionality for } \\
\text { devices }\end{array}$ & $\begin{array}{l}\text { MANET, } \\
\text { WSN, and } \\
\text { VANETs }\end{array}$ \\
\hline GloMoSim/QualNet & & $\begin{array}{l}\text { Random WayPoint, } \\
\text { Random Walk, } \\
\text { Manhattan Grid, Gauss- } \\
\text { Markov model, } \\
\text { Reference Point Group } \\
\text { Mobility, and Group } \\
\text { Mobility }\end{array}$ & $\mathrm{C}$ & $\begin{array}{l}\text { It can scale up to } \\
\text { networks with } \\
\text { thousands of } \\
\text { heterogeneous } \\
\text { nodes. }\end{array}$ & $\begin{array}{l}\text { MANET, } \\
\text { WSN, and } \\
\text { VANETs }\end{array}$ \\
\hline SSFNet & & $\begin{array}{l}\text { Random WayPoint, } \\
\text { Random Walk, } \\
\text { Manhattan Grid, Gauss- }\end{array}$ & Java and C++ & $\begin{array}{l}\text { Scalable, high- } \\
\text { performance } \\
\text { network }\end{array}$ & $\begin{array}{l}\text { MANET, } \\
\text { WSN, and } \\
\text { VANETs }\end{array}$ \\
\hline
\end{tabular}




\section{SURVEY ARTICLE}

\begin{tabular}{|c|c|c|c|c|c|}
\hline & & $\begin{array}{l}\text { Markov model, and } \\
\text { Reference Point Group } \\
\text { Mobility }\end{array}$ & & modeling & \\
\hline J-Sim & & Random WayPoint & Java & $\begin{array}{l}\text { Supports energy } \\
\text { modeling, } \\
\text { component-based } \\
\text { architecture }\end{array}$ & WSN \\
\hline GTNets & $\begin{array}{l}\text { Network } \\
\text { Simulator }\end{array}$ & Random WayPoint & $\mathrm{C}++$ & & $\begin{array}{l}\text { MANET, } \\
\text { WSN, and } \\
\text { VANETs }\end{array}$ \\
\hline
\end{tabular}

Table 2 Network Simulators and Mobility Models

Several mobility models are developed for various MWNs [12] [14]. The research works build communication networks using both experimental and mathematical models to prove the performance. In the last decade, communication networks have become too complex for mathematical analysis. Thus, network designers prefer simulation tools for analyzing the behavior and performance of the networks and their protocols. The network simulation tools are often used in testing the capacity of networks to meet the quality of service. Also, the simulation tools can explore a wide range of potential protocols for evaluating wireless network performance.

\subsection{Scope and Motivation of the Survey}

The advancement of information and communication technology has created a potential opportunity for the expansion of MWNs. Many successful wireless network solutions deployed for practical use are purely depending on the groundwork of MWNs. A wide range of network extensions of MWNs has been successfully deployed in the market, for instance, MANET, FANET, WSN, VANET, mobile opportunistic network, Delay Tolerant Networks (DTN), Underwater Wireless Sensor Networks (UWSN), and Internet of things. This network expansion offers excellent scope for evaluating geographical routing protocols under various network environments and mobility models. The motivation of the survey is to offer a comprehensive survey that studies the impact of geographical routing under various mobility models for the extensions of MWNs. Recent advances in GPS technology and the growing popularity of positioning devices enable the added advantage of geographical routing protocols over the other routing protocols. Geographical routing protocols significantly overcome topology-based routing pitfalls due to the high scalability and robustness against dynamic topology changes. It potentially reduces the high resource and communication cost of topology-based routing protocols in the high mobility network environment. It also enables the scalability of the routing protocol to support large-scale networks with limited overhead in a dynamic network environment. Considering these advantages, MWNs effectively utilize the geographical routing protocols for various networks and application scenarios. With the advancement of new technologies, devices start to shrink in size and can process and hold large volumes of data. As a result, the market witnessed tremendous growth of mobile devices within a short period. Mobile devices are expanding the capabilities of the network to the next generation of MWNs. Researchers have studied the movement patterns of human beings and animals. Human mobility is highly complex and mainly influenced by social aspects. Thus, creating mobility models that mimic human mobility and evaluating the protocols under various network conditions is essential for reliable and efficient routing operations. Performance evaluation is an essential and integral part of any network research and developing a new mobility model largely depending on the mobility of the device.

\subsection{Contributions}

This survey highlights the recent MWN research trends that explore geographical routing under various mobility models and network environments. It explores how geographical routing can help MWNs achieve their full potential under different mobility scenarios and applications. The literature reveals that surveys are published for mobility models [15] [16] [17] and geographical routing protocols [9] that focus only on a specific network and protocol. The primary contribution of this survey is that it compares the most popular extensions of MWNs and their behavior with different mobility models based on geographical routing protocols. The primary focus of this survey is to assist researchers in designing the models of various MWNs and extensions with appropriate mobility model and suitable geographical routing protocols. This work motivates future research in MWNs to model the wireless networks 


\section{SURVEY ARTICLE}

appropriately with the realistic motion of wireless devices and design an efficient geographical routing by solving the issues in conventional routing schemes.

\subsection{Paper Organization}

Section 2 presents the geographical routing protocols in MWNs. Different geographical routing protocols are explored, such as greedy-based routing, face routing, greedyface-greedy routing, and opportunistic routing. Section 3 presents various mobility models for geographic routing in MWNs and extensions. Section 4 investigates the impact of mobility issues and mobility adaptive location update schemes on geographical routing protocols. Section 5 presents the latest trends and future directions, and Section 6 concludes the survey.

\section{GEOGRAPHICAL ROUTING PROTOCOLS FOR MWNS}

Recently, MWNs have embraced geographical routing protocols for many potential applications due to their stateless property, scalability, and efficiency. It widely supports energy efficiency, Quality of Service (QoS), node mobility, and context awareness. Geographic routing algorithms employ position information such as its position, position of neighbors, and destination position to make packet forwarding decisions [9]. It delivers data packets in a network over multiple hops utilizing location information. This process makes geographic routing more attractive for dynamic wireless network scenarios. Geographic routing also supports context-aware routing decisions based on location information that leads to the establishment of ubiquitous computing. The geographic routing protocols employ location servers for the sources to obtain the position of the destination. Each node updates its location information to the location servers using a handful of messages. For scalable wireless communication, the nodes have to know only the location of their neighboring nodes for data routing. It eliminates the need for state propagation and flooding beyond the one-hop distance. The geographical routing provides a fast response to the frequent topology changes and discovers new routes quickly. Thus, geographical routing by utilizing the advantages of node mobility is an attractive method for MWNs.

\subsection{Classification of Geographic Routing}

The geographic routing protocol classifies into four significant methods: greedy-based routing, face routing, greedy-face-greedy routing, and opportunistic routing, as shown in figure 1 . Greedy forwarding is the earliest routing approach in which the data packets are routed to the neighboring node closer to the destination [18]. Compass routing is a basic model for face routing, and it successfully detects when a node crosses a line connecting the source and destination [19]. The first face routing algorithm is executed by applying the compass algorithm to Unit Disk Graphs (UDG) and planarizing UDG [20].

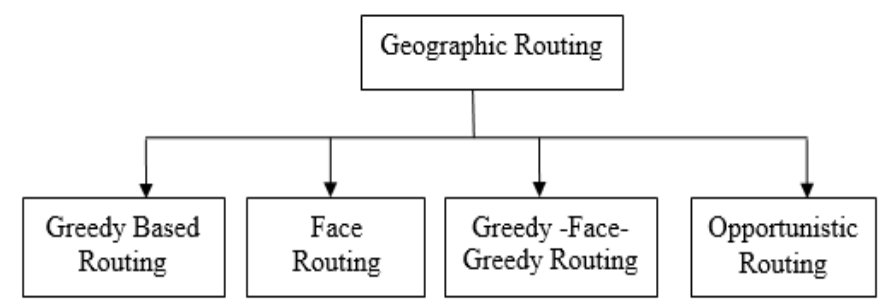

Figure 1 Classification of Geographic Routing Protocol

\subsubsection{Greedy Based Routing}

The Greedy based routing is a simple, easy to implement, and understandable geographic routing. When a source wishes to forward the data packets to a destination in greedy routing, it consults the neighbor table to determine a next-hop node closer to the destination. However, greedy routing does have a significant problem when a node has an empty neighbor list to reach the destination; it drops the data packets, referred to as local maximum or void problem [21]. The local maximum problem provides a severe issue for the performance of greedy forwarding. An extension of basic greedy routing employs the concept of the potential field [22]. The possible fields are used in the movement using the virtual repulsive force.

\subsubsection{Face Routing}

An alternative method called face routing is applied to overcome the problems faced by greedy forwarding, which builds planar sub-graphs using a polarization mechanism [23]. In the planarization process, the intersecting edges are removed in a network graph to construct the planar graph and avoid segmentation. A UDG consists of circles and a line where two circles are overlapped, indicating communication links. A UDG can model a mobile ad hoc network where the vertices signify the nodes placed on the Euclidean plane. When the transmission range of two nodes is overlapping, they can communicate with each other. An Adaptive Face Routing (AFR) binds the cost of determining the destination into the routing function. However, due to the limitation of its searching area, the Bounded Face Routing (BFR) with the elliptical shape increases the number of hops that augment the data delay and overhead on routing [24]. A drawback of the right-hand rule method used in UDG is blind packet traversal, leading to a long path and substantial data delay. The claim of incorrect faces in face routing protocols leads to inefficient routing over highly dynamic environments.

\subsubsection{Greedy-Face-Greedy Routing}

The Greedy-Face-Greedy routing protocol or hybrid routing combines both greedy and face routing, where it starts as the greedy routing protocol and switches to face routing in the 


\section{SURVEY ARTICLE}

absence of neighbors. Greedy Other Adaptive Face Routing (GOAFR) [25] builds hybrid greedy and face routing. It uses the greedy mode until the local maximum problem is encountered, and OAFR is employed as a recovery scheme for the void problem. Once the face routing, OAFR is initialized and continued until it reaches the destination or the greedy mode is possible to reach the destination. The extension of GOAFR (GOAFR+) is a hybrid greedy-face routing, and it is asymptotically optimal routing [26]. The main difference between the GOAFR and GOAFR+ is that it does not take the full boundary of a face, instead of using two counters to keep the greedy neighbors closer to the destination. A Greedy Path Vector Face Routing (GPVFR) is a non-oblivious method that guarantees efficient packet delivery without complete face information and improves the routing efficiency of both hop stretch and path stretch [27].

\subsubsection{Opportunistic Routing}

A new routing paradigm, named Opportunistic Routing (OR), exploits the benefits of the wireless medium with a broadcasting nature. Unlike conventional routing protocols, OR selects forwarding candidates instead of choosing a specific packet forwarder. It allows further candidates to store and forward the overheard data packet. The forwarding candidate list is similar to routing table maintenance in conventional routing, but it can be global or local, depending on the routing strategy. Multiple nodes can overhear the same packet, even when a node forwards a packet to a specific node [28-29]. Typically, a source node maintains the global forwarding set, while the local forwarding set is distributed among candidates. All the forwarding candidates need to be coordinated according to some criteria for opportunistically routing the data packets without duplication. The OR protocol transmits a packet through any available links rather than a selected single link, and in other words, additional backup the availability of nodes in OR reduces the node mobility impact on packet delivery dramatically. Therefore, the OR increases the robustness of multihop wireless communication.

\subsubsection{Void Handling in Geographical Routing}

Generally, the number of intermediate routers is decreased due to void areas in sparse networks. The presence of void areas in the various network area is a severe limitation in geographic data forwarding. In the presence of a void area, the geographic routing protocols often fail to deliver the data packets at the destination successfully. In such a case, the data packets are dropped in the void area, and further, they are not transmitted due to neighbor unavailability. Due to the random node topology and dynamic node mobility, detecting the void area is not easy in wireless networks. Flooding is the simplest void avoidance method that provides the least routing path for successful data transmission in wireless networks [30]. The network nodes receive multiple unnecessary copies for single data transmission. Thus the flooding method is inefficient, as it consumes high energy and bandwidth in resourceconstrained networks.

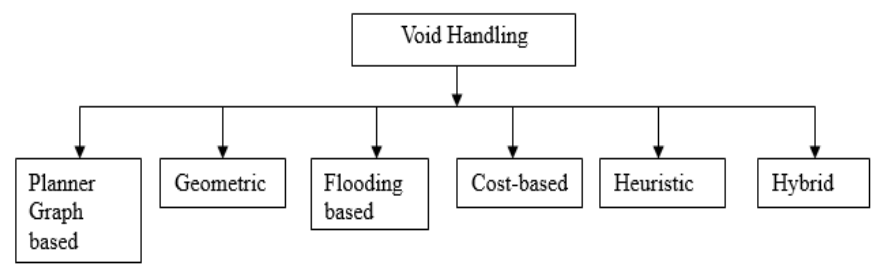

Figure 2 Classification of Geographic Void Handling Techniques

Figure 2 depicts the classification of geographic void handling mechanisms and techniques are categorized by floodingbased, planar graph-based, cost-based, geometric, heuristic, and hybrid [31].

\section{MOBILITY MODELS FOR MULTI-HOP WIRELESS NETWORKS}

Performance evaluation using a simulator is paramount to assess the efficacy of any newly proposed MWN protocols. The routing process mainly depends on the stability of the wireless links, which again rely on the mobility of the network nodes. The mobility models are the foundation to emulate real-time mobility scenarios. As the mobility model creates a significant impact on routing efficiency, it must capture the mobility characteristics of devices realistically. The selection of the mobility model is prominent in simulation because the assumptions on the mobility models create a strong influence on the node trajectories, resulting in a drastic effect on routing performance. Wireless network research emphasizes new mobility models that mimic the movement characteristics of humans, mobile devices, and vehicles realistically. Generally, the factors of location, moving direction, node velocity, and velocity changes over time govern the nature of real-time mobility.

Figure 3 depicts a popular classification of existing multihop wireless network mobility models. A detailed survey of mobility models available in the literature [12] [14][16][17][32][33]. Recent research works focus on the distribution of these factors on emulating the movement nature that could be observed in real-time in the design of mobility models. Therefore, mobility models are classified based on different factors related to node mobility factors. Multiple classifications exist according to various parameters such as mobility prediction, randomness, and node mobility behavior. According to the mobility prediction, the mobility models can be divided into deterministic, semi-deterministic, and random mobility. The mobility models are also classified into a statistical, constrained, and the trace-based mobility model based on the degree of randomness. The mobility models are organized into traces and synthetic mobility models according to the behavior of mobile nodes. 


\section{SURVEY ARTICLE}

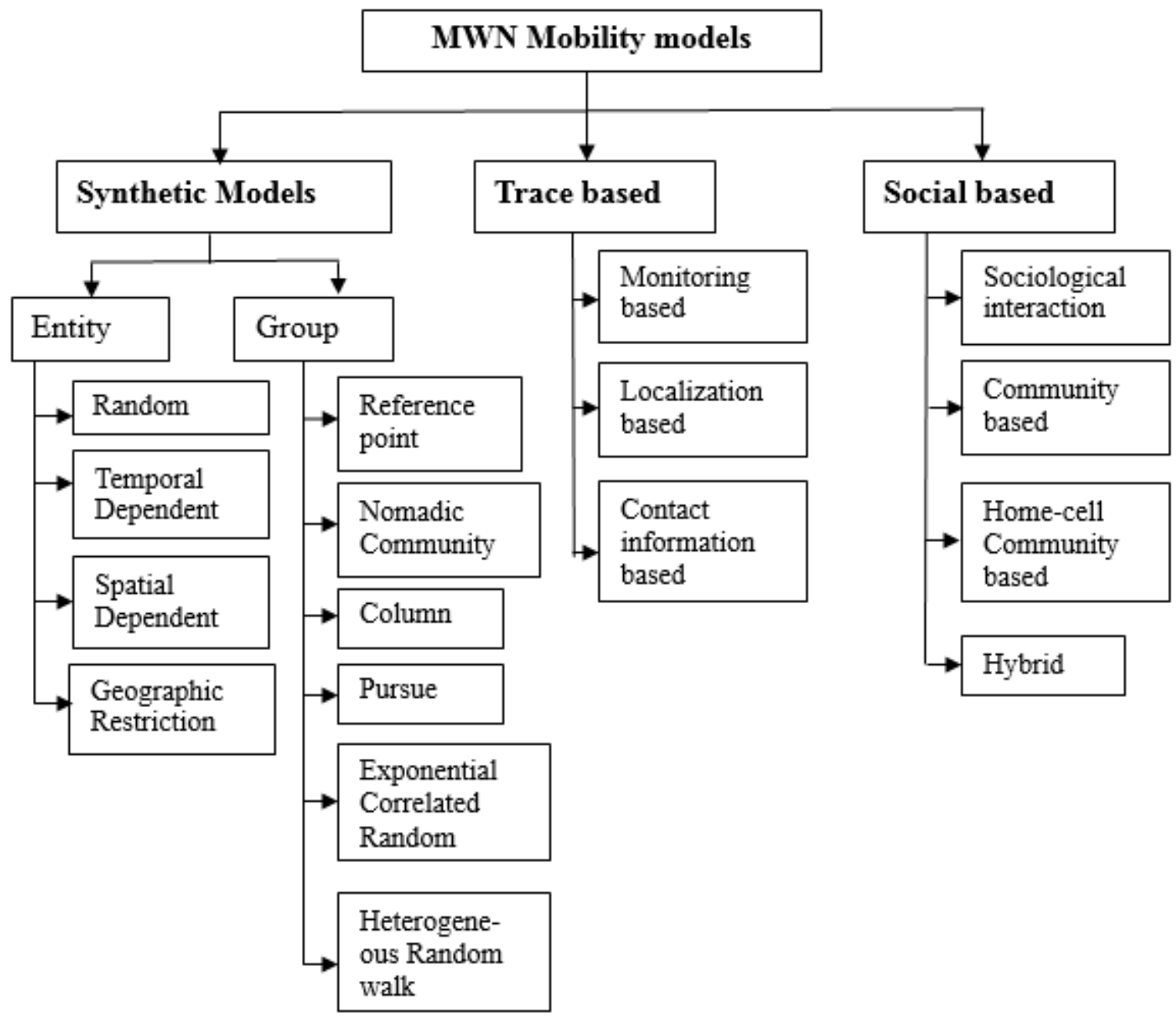

Figure 3 Classification of Mobility Models

Individual node mobility has a minor impact on multihop routing than a group of node mobility. Generally, the mobility models proposed for multihop wireless networks are crossdisciplinary, and it is non-viable to provide exhaustive classification about existing mobility models. Many factors have been used in the literature to classify the existing mobility models in wireless multihop networks. Entity versus group mobility behavior is mainly used to categorize the mobility models, and another classification factor is whether the mobility models account for the obstacles such as geometric vs. non-geometric, free space vs. geographic, and guided vs. unguided. Most of the classification schemes divide the models into five categories: synthetic, trace-based, social-based, vehicular, and human mobility.

The trace-based models observe the real-time applicationoriented node mobility. The real-time mobility traces are performed in three categories: monitoring-based, localizationbased, and contact information-based. The monitoring-based trace mobility models observe the mobility information through straight monitoring. Secondly, the localization-based model utilizes location information to know the movement of the nodes. Finally, contact information like mobile phone numbers and addresses are utilized to observe the node mobility. The dynamic network topology induced by high mobility nodes and lengthy observation periods poses significant challenges in the trace of node mobility. In the absence of traces, synthetic mobility models are essential to describe realistic node movements. The entity and group mobility models are the two main classifications of synthetic models. Further, the entity mobility models are segregated into random, temporal dependent, spatial dependent, and geographic restriction. Mostly, wireless network applications utilize entity mobility models based on random motions. In the random-based entity mobility, frequently used models are the RW and RD. The mobility models are grouped under the temporal, spatial, and geographic categories according to the dependencies and restrictions on node movement. The 


\section{SURVEY ARTICLE}

dependencies on the past movement behavior of nodes and the behavior of the surrounding nodes considerably influence the temporal and spatial category. Further, the RPG mobility model is widely used in the group category. The other group entity mobility models are the nomadic community, column, pursue, heterogeneous random walk, and exponential correlated random. The social-based mobility models are divided into community-based, sociological interaction, home-cell community-based, and hybrid. Most of the existing mobility models fall into the hybrid category in which more than one type of social mobility model is integrated.
The following section is dedicated to mobility models applied to geographical routing protocols for various MWNs such as MANET, FANET, WSN, VANET, and DTN.

\subsection{Mobility Models for MANET}

It is necessary to analyze the node mobility during the routing phase in the MANET, and several works have been proposed in mobility characterization under different mobility patterns. Individual node mobility has a minor impact on MANET routing than a group of node mobility. Some of the MANET mobility models are listed in Table 3.

\begin{tabular}{|c|c|c|c|c|c|c|}
\hline \multirow{2}{*}{ Mobility Models } & \multirow{2}{*}{$\begin{array}{c}\text { Node } \\
\text { Pattern }\end{array}$} & \multirow{2}{*}{$\begin{array}{l}\text { Pause } \\
\text { Time }\end{array}$} & \multicolumn{4}{|c|}{ Support on Mobility Metrics } \\
\hline & & & $\begin{array}{c}\text { Moving } \\
\text { Direction }\end{array}$ & Speed & $\begin{array}{c}\text { Time } \\
\text { Correlation }\end{array}$ & $\begin{array}{c}\text { Spatial } \\
\text { Correlation }\end{array}$ \\
\hline $\begin{array}{c}\text { Random } \\
\text { Way Point }\end{array}$ & Individual & Yes & Randomly Chosen & Uniformly chosen & No & No \\
\hline $\begin{array}{l}\text { Random } \\
\text { Walk }\end{array}$ & Individual & No & Randomly Chosen & Randomly Chosen & Yes & Yes \\
\hline $\begin{array}{c}\text { Random } \\
\text { Direction }\end{array}$ & Individual & Yes & Uniformly chosen & Randomly Chosen & Yes & Yes \\
\hline $\begin{array}{c}\text { Reference } \\
\text { Point Group }\end{array}$ & $\begin{array}{c}\text { Group } \\
\text { Movement }\end{array}$ & No & Uniformly chosen & Uniformly chosen & No & Yes \\
\hline $\begin{array}{c}\text { Community-Based } \\
\text { Mobility Model }\end{array}$ & $\begin{array}{c}\text { Group } \\
\text { Movement }\end{array}$ & No & $\begin{array}{c}\text { Intrinsic, } \\
\text { derived from } \\
\text { target attraction } \\
\text { computation } \\
\end{array}$ & Uniformly chosen & Yes & Yes \\
\hline $\begin{array}{c}\text { Simple } \\
\text { Human } \\
\text { Mobility Model }\end{array}$ & $\begin{array}{c}\text { Group } \\
\text { Movement }\end{array}$ & No & $\begin{array}{c}\text { Intrinsic, } \\
\text { derived from } \\
\text { target attraction } \\
\text { computation }\end{array}$ & $\begin{array}{l}\text { Cumulative, } \\
\text { depends on all } \\
\text { nodes' speed }\end{array}$ & Yes & Yes \\
\hline $\begin{array}{l}\text { Time-Variant } \\
\text { Community } \\
\text { Model }\end{array}$ & $\begin{array}{c}\text { Group } \\
\text { Movement }\end{array}$ & Partially & Uniformly chosen & Uniformly chosen & Yes & Yes \\
\hline
\end{tabular}

Table 3 Mobility Models for MANET

Random Models: The Random Way Point (RWP) is the basic model, and it is the foundation for other mobility models in wireless networks. The mobility pattern of nodes includes the pause time for varying the network topology. It means a mobile node stays in the exact location after its every mobility. A Random Direction (RD) is a primary model proposed in wireless networks in which the mobile nodes move all the way to cover the network area. It avoids the overlapped nodes or high density in the center of the network due to the mobility characteristics of the RWP model over time.

Models with Temporal Dependency: In random dependency, the entity or individual mobility represents the nodes whose mobility is independent of each other - RWP, RD, and Random Walk Mobility (RWM) model. The random selection of mobility parameters, such as node speed, moving direction, and time, is independent of each other. The group mobility declares that each node's movement is dependent on others in its group. The most general group mobility models for the MANET environment is Reference Point Group Mobility (RPGM) model. The temporal dependence represents how the velocity changes in individual node mobility over a particular time, and each node moves according to its movement history.

Models with Spatial Dependency: The correlated movement of nodes in the network, named the degree of spatial dependence. The increased number of mobile nodes moving in the same direction with the same speed increases the degree of spatial dependence. The most predictable node mobility in MANET is the deterministic mobility model. When the direction of two mobile nodes is equal, the deviation of the direction vectors of the two positions is zero. The mobile 


\section{SURVEY ARTICLE}

node moves in a straight line, and it turns only at the bend. This category of mobility model is called as Urban Traffic Model. Still, some of the applications are failing to determine the node's mobility accurately. The individual mobile nodes do not move in a specific direction but follow a particular mobility pattern. For instance, consider the movement of ants as they walk in the general direction.

Models with Geographical Restriction: Generally, the graph-based model works based on vertices and edges in which vertices represent the intended destinations and edges denote the possible communication routes to the intended destinations. Different approaches have been employed to explore node mobility restriction in a particular area, and these are area graph, geographic division, map, and Voronoibased approach [34]. In a real environment, random mobility is not always possible. A graph-based method is proposed to handle this kind of problem. Generally, the area graph-based mobility model classifies the geographical area into clusters with high node density, whereas the map-based mobility model restricts the node movement in the network.

\subsubsection{Mobility Models Applied to Geographical Routing in MANETs}

Some traditional mobility models, such as random, correlated, and restricted random models, have been adapted to model MANETs. The most general way to use these random mobility models is to configure the mobility factors such as speed, range, variance, simulation area, and time depending on applications. Moreover, the restricted random walk model describes the movement of mobile nodes in a restricted area. The random mobility models are used to get insights into MANET networking performance. The Gauss Markov mobility models are mostly used to model the personal communication system in a MANET environment. The GPSR [18] and GLR [21] are the most fundamental geographical routing protocols proposed for MANETs. Such protocol employs the simple random waypoint mobility model in simulations. Consequently, some of the other greedy routing protocols are Geographic Direction Forwarding Routing (Geo-DFR) [35], Normalized ADVance (NADV) based routing [36], Greedy Routing Protocol with Backtracking (GRB) [37], Energy and Mobility Greedy Perimeter Stateless Routing (EM-GPSR) [38], prediction new link lifetime for greedy and contention-based routing [39], and Efficient position based Most Forward within Radius (MFR) [40] also utilizes the random mobility models in their simulations. The contention-based routing in [39] employs link lifetime in router selection and selects high stability links for routing. The main intention of Geo-DFR is to make better routing decisions based on the geographical location and destination direction. The NADV offers an effective mobility-aware routing method to MANETs. The GRB and EM-GPSR routing protocols effectively deal with void issues in greedy MANET routing and maximize routing efficiency. Further, the MFR routing protocol boosts the routing performance by determining suitable position-based routers. The face routing protocol Efficient Particle Swarm based Resource Optimized Geographic Routing (PS-ROGR) [41] and Novel geographic routing scheme [42] exploit random models, whereas Qlearning based geographic routing (QGeo) [43] uses Gaussian Markov mobility model. The greedy face routing protocols GOAFR [25], GOAFR+ [26], and Topology Aware Geographic Routing (TAG) [44] combines the advantages of greedy and face routing in router selection, resulting in better geographic routing performance. Such models consider the random mobility models in simulation. Similarly, the opportunistic routing protocols Fuzzy Logic Q-learning Based Asymmetric Link Aware and Geographic Opportunistic Routing (FQ-AGO) [45], Reliable and practical opportunistic routing protocol, named as ORGMA [46], Cross-Layer Reliable Opportunistic Routing (CBRT) [47], and Cooperative Opportunistic Routing scheme in Mobile Ad hoc Networks (CORMAN) [48] also employ simple random mobility models for performance analysis. The adaptation of various mobility models over MANETs is discussed in Table 4.

\begin{tabular}{|c|c|c|c|c|}
\hline Routing Protocol & Category & Routing Objective & $\begin{array}{l}\text { Mobility } \\
\text { Model }\end{array}$ & Advantages \\
\hline GPSR [18] & & Maximum progress & $\begin{array}{l}\text { Random } \\
\text { waypoint }\end{array}$ & Loop free Routing \\
\hline GLR [21] & & $\begin{array}{l}\text { Avoiding unnecessary } \\
\text { longer traversal paths }\end{array}$ & $\begin{array}{l}\text { Random } \\
\text { waypoint }\end{array}$ & $\begin{array}{l}\text { Neglecting triangular } \\
\text { routing reduces the delay }\end{array}$ \\
\hline Geo-DFR [35] & & $\begin{array}{l}\text { Making direction based } \\
\text { routing decisions }\end{array}$ & $\begin{array}{l}\text { Random } \\
\text { waypoint }\end{array}$ & $\begin{array}{l}\text { Higher delivery ratio with } \\
\text { minimum overhead }\end{array}$ \\
\hline NADV [36] & Greedy & $\begin{array}{l}\text { The optimal tradeoff } \\
\text { between proximity and } \\
\text { link cost }\end{array}$ & $\begin{array}{l}\text { Random } \\
\text { waypoint }\end{array}$ & $\begin{array}{llr}\begin{array}{l}\text { Efficient and } \\
\text { adaptive }\end{array} & \text { mobility } \\
\text { routing strategy } & \end{array}$ \\
\hline
\end{tabular}




\section{SURVEY ARTICLE}

\begin{tabular}{|c|c|c|c|c|}
\hline GRB [37] & Routing & $\begin{array}{l}\text { To deal with voids and } \\
\text { improve routing } \\
\text { efficiency }\end{array}$ & $\begin{array}{l}\text { Random } \\
\text { waypoint }\end{array}$ & $\begin{array}{l}\text { Lower end-to-end delay, } \\
\text { Overhead, and minimum } \\
\text { hop count }\end{array}$ \\
\hline EM-GPSR [38] & & $\begin{array}{l}\text { Improves a method to } \\
\text { deal with routing voids }\end{array}$ & $\begin{array}{l}\text { Random } \\
\text { waypoint }\end{array}$ & $\begin{array}{ll}\text { Less } & \text { computational } \\
\text { complexity }\end{array}$ \\
\hline $\begin{array}{l}\text { Contention-based } \\
\text { routing [39] }\end{array}$ & & $\begin{array}{l}\text { It aims to select better } \\
\text { next-hop with high link } \\
\text { stability }\end{array}$ & $\begin{array}{l}\text { Random } \\
\text { waypoint }\end{array}$ & $\begin{array}{l}\text { Reduced end-to-end delay } \\
\text { and higher delivery ratio }\end{array}$ \\
\hline MFR [40] & & $\begin{array}{l}\text { To determine the most } \\
\text { suitable intermediate } \\
\text { nodes using position } \\
\text { information }\end{array}$ & $\begin{array}{l}\text { Random } \\
\text { waypoint }\end{array}$ & $\begin{array}{l}\text { Optimizing the routing } \\
\text { performance } \\
\text { considering the velocity } \\
\text { issues in advance }\end{array}$ \\
\hline PS-ROGR [41] & \multirow{3}{*}{ Face Routing } & $\begin{array}{l}\text { Selecting better routers } \\
\text { based on PSO based } \\
\text { location fitness }\end{array}$ & $\begin{array}{l}\text { Random } \\
\text { waypoint }\end{array}$ & $\begin{array}{lr}\text { Energy-efficient } & \text { routing } \\
\text { and maximum network } \\
\text { lifetime }\end{array}$ \\
\hline $\begin{array}{lr}\text { Novel } & \text { geographic } \\
\text { routing } & \text { scheme } \\
{[42]} & \end{array}$ & & $\begin{array}{l}\text { Dealing with critical } \\
\text { communication voids in } \\
\text { sparse MANETs }\end{array}$ & $\begin{array}{l}\text { Random } \\
\text { Way Point }\end{array}$ & $\begin{array}{l}\text { Minimum overhead and } \\
\text { delay for handling the } \\
\text { communication voids }\end{array}$ \\
\hline QGeo [43] & & $\begin{array}{l}\text { Minimize the overhead } \\
\text { under high mobility } \\
\text { scenario }\end{array}$ & $\begin{array}{l}\text { Gaussian } \\
\text { Markov } \\
\text { random } \\
\text { mobility }\end{array}$ & $\begin{array}{l}\text { Enhanced packet delivery } \\
\text { ratio improved the } \\
\text { performance of robotics }\end{array}$ \\
\hline GOAFR [25] & \multirow{3}{*}{$\begin{array}{l}\text { Greedy-Face- } \\
\text { Greedy } \\
\text { Routing }\end{array}$} & Adaptive face Routing & $\begin{array}{l}\text { Random } \\
\text { Model }\end{array}$ & High Scalability \\
\hline GOAFR+ [26] & & $\begin{array}{l}\text { Reducing the delay of } \\
\text { GOAFR }\end{array}$ & $\begin{array}{l}\text { Random } \\
\text { Model }\end{array}$ & $\begin{array}{l}\text { Restricted } \quad \text { boundary } \\
\text { traversal }\end{array}$ \\
\hline TAG [44] & & $\begin{array}{l}\text { Reducing the number of } \\
\text { hops and improved } \\
\text { local forwarding } \\
\text { decisions }\end{array}$ & $\begin{array}{l}\text { Random } \\
\text { waypoint }\end{array}$ & $\begin{array}{l}\text { Supporting for node } \\
\text { mobility and void handling }\end{array}$ \\
\hline FQ-AGO [45] & \multirow{4}{*}{$\begin{array}{l}\text { Opportunistic } \\
\text { Routing }\end{array}$} & $\begin{array}{l}\text { It aims to assign long- } \\
\text { range transmission } \\
\text { links for routing }\end{array}$ & $\begin{array}{l}\text { Modified } \\
\text { random } \\
\text { waypoint }\end{array}$ & $\begin{array}{l}\text { Improved communication } \\
\text { reachability, maximum } \\
\text { scalability, and improved } \\
\text { packet delivery with } \\
\text { reduced end-to-end delay }\end{array}$ \\
\hline ORGMA [46] & & $\begin{array}{l}\text { Adopts a gradient } \\
\text { forwarding approach }\end{array}$ & $\begin{array}{l}\text { Random } \\
\text { waypoint }\end{array}$ & $\begin{array}{lrr}\text { Achieve } & \text { high } & \text { packet } \\
\text { delivery } & \text { ratio } & \text { under } \\
\text { dynamic } & & \text { MANET } \\
\text { environments } & \\
\end{array}$ \\
\hline CBRT [47] & & $\begin{array}{l}\text { Employs the fuzzy } \\
\text { logic to regenerate the } \\
\text { dead nodes }\end{array}$ & $\begin{array}{l}\text { Random } \\
\text { model }\end{array}$ & $\begin{array}{l}\text { Minimizes the data loss } \\
\text { and balance the efficiency } \\
\text { of transmission }\end{array}$ \\
\hline CORMAN [48] & & $\begin{array}{l}\text { To determine a list of } \\
\text { better intermediate } \\
\text { nodes }\end{array}$ & $\begin{array}{l}\text { Random } \\
\text { Waypoint }\end{array}$ & $\begin{array}{l}\text { Better routing performance } \\
\text { with minimum overhead }\end{array}$ \\
\hline
\end{tabular}

Table 4 Mobility Models Applied to Geographical Routing Techniques over MANETs 


\section{SURVEY ARTICLE}

\subsection{Mobility Models for UAV and FANET}

UAVs collaboratively perform a task without a human intervention applied for military surveillance, disaster management, and other valuable real-time services. In UAV networks, the UAV devices such as drones and aircraft collaboratively monitor and gather data about the particular region and transmit the information to a ground station for taking appropriate actions. Routing is a significant task in UAV networks, and the routing protocol design poses several challenges in UAVs, particularly the high mobility due to the speed of UAVs. Hence, the UAVs move with a high degree of node mobility, and the speed is relatively $30-460 \mathrm{~km} / \mathrm{h}$. Before implementing the novel UAV routing protocols straightly in real-time application services, it is essential to evaluate its performance using a simulator. The efficiency of UAV routing protocols mainly depends on mobility, and the mobility models play a more significant role in generating the movement patterns of the UAVs in simulation. Designing an appropriate mobility model is essential to precisely evaluate the movement patterns of UAVs based on the application type. Notably, the specific mobility of UAVs affects simulation performance. Generally, the UAVs have similar characteristics of MANETs, and they use the mobility models of MANET, such as random and Gauss Markov models for evaluation. These models fail to accurately reflect the mobility patterns of UAVs, resulting in misleading simulation results. The speed of UAVs is high compared with MANETs, and it poses significant challenges in routing protocol design. Such an issue is not adequately handled due to the actual behavior of UAVs in real-world applications. New mobility models specially proposed for UAV networks consider the speed variations and unpredictable location changes of UAV nodes. The mobility models proposed for UAVs are mainly categorized into five categories: pure randomized, time dependant, path-planned, group mobility, and topology control-based. Discussions on the FANET mobility models are available in [49]. A comparative analysis of such mobility models is depicted in table 5.

\subsubsection{Mobility Models Applied to Geographical Routing in UAV and FANET}

UAVs are envisioned in several real-world applications such as surveillance, rescue operations, and disaster in the modern world [50]. According to the application, selecting an adaptable mobility model is essential, as the movement patterns of UAVs differ according to the application type. A survey of position-based routing for FANET is discussed in [51][52]. The fundamental and straightforward random mobility models such as RW, RWP, and RD are widely employed to analyze wireless network performance. In recent years, such models have been adapted to UAVs for analyzing performance by selecting appropriate parameters such as node speed and density that reflect UAV network characteristics.
The fundamental random mobility models only express the ordinary random movements of nodes. They are not considering the realistic movements of nodes, such as frequent changes in node mobility, correlations among node directions, and relations between mobile network entities. Due to the removal of such information, adopting simple random mobility models is the most natural way of evaluating UAV performance. The simplest way to adapt random mobility models for UAV is to consider the random speed of the nodes, and the simulation area size depends on UAV settings in the simulation parameter configuration. The UAV random models easily capture the high mobility of UAV nodes. In contrast, it ignores the correlations among UAVs over a particular period in spatial and temporal dimensions, resulting in wrong direction changes. The random models select random time slots for observation and create nonsmooth unrealistic trajectories in UAV simulation. Therefore, it is crucial to assess the performance of UAVs with diverse mobility models with various configuration settings. The path plan-based mobility models have pre-defined path movement trajectories, and it is more adaptable for UAVs in transportation scenarios in which the UAVs knew their destination. The semi-random circular movement mobility models include a pre-defined turn center, resulting in restricted random trajectories. Such models are employed in application scenarios that predetermine the position information of a target. The smooth turn mobility models are suitable for patrolling applications that express realistic and flexible trajectories. The Gauss Markov mobility model overcomes the issues of random models by providing rich insights into the parameter configuration of UAVs.

Most of the UAV geographic routing protocols utilize random mobility models. UAV-Assisted VANET Routing Protocol (UVAR) [53], UAV Search Mission Protocol (USMP) presented for swarming UAVs to improve the search performance [54], and Greedy forwarding geographical routing on the Internet of Drones [55] exploit random mobility models in simulation. A reliable link-adaptive position-based routing protocol (RLPR) is proposed in [56] that establishes high connectivity level by selecting the relay nodes based on energy level, signal strength, and relative speed. Another greedy routing protocol, Geographic Position Mobility Oriented Routing (GPMOR) [57] employs the gauss markov mobility model and rectifies the issues associated with random models. Consequently, the aircraft UAV opportunistic routing protocols Location-Aware Routing for Opportunistic Delay Tolerant (LAROD) [58] and Aeronautical Routing Protocol (AeroRP) [59] maximizes the communication efficiency by successfully delivering the packets using store and carry forward mechanisms. Such models incorporate simple random mobility patterns for evaluation. The drone UAV protocols Cross-layer Link quality and Geographical-aware beaconless opportunistic 


\section{SURVEY ARTICLE}

routing protocol (XLinGo) [60], Location-aided delay-tolerant routing (LADTR) [61], Vehicle-Drone hybrid vehicular ad hoc Network (VDNet) [62], Connectivity-based Traffic Density Aware Routing using UAVs (CRUV) [63], and All Neighbors Opportunistic Routing (ANOR) [64] use simple random movement patterns. In contrast, the course-aware

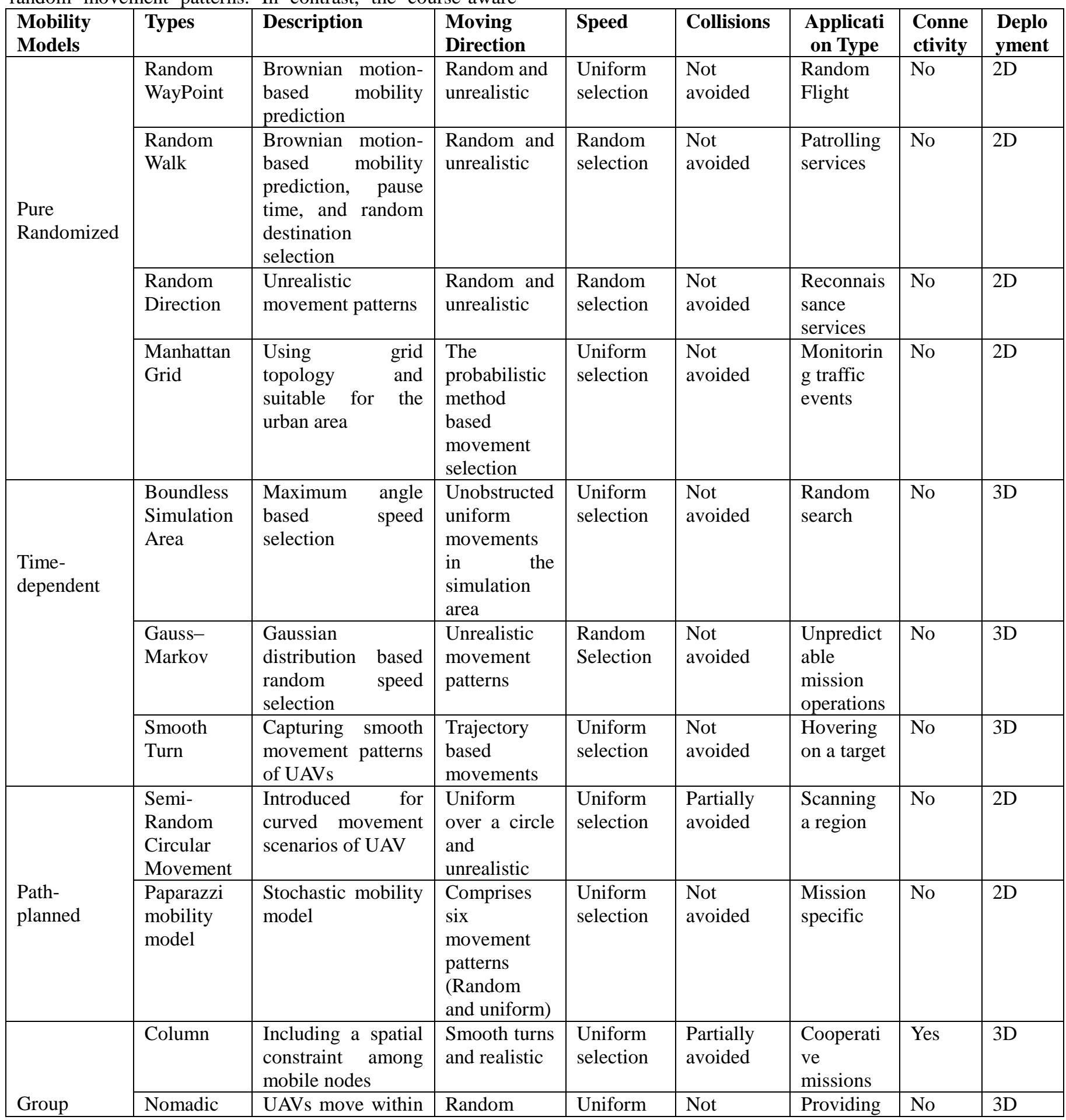

opportunistic routing for FANETs (CORF) [65] exploits the shortest path map-based mobility pattern for performance analysis. Table 6 discusses the various mobility models applied to geographic routing protocols proposed for UAV networks. 
International Journal of Computer Networks and Applications (IJCNA)

DOI: 10.22247/ijcna/2021/209993 Volume 8, Issue 5, September - October (2021)

SURVEY ARTICLE

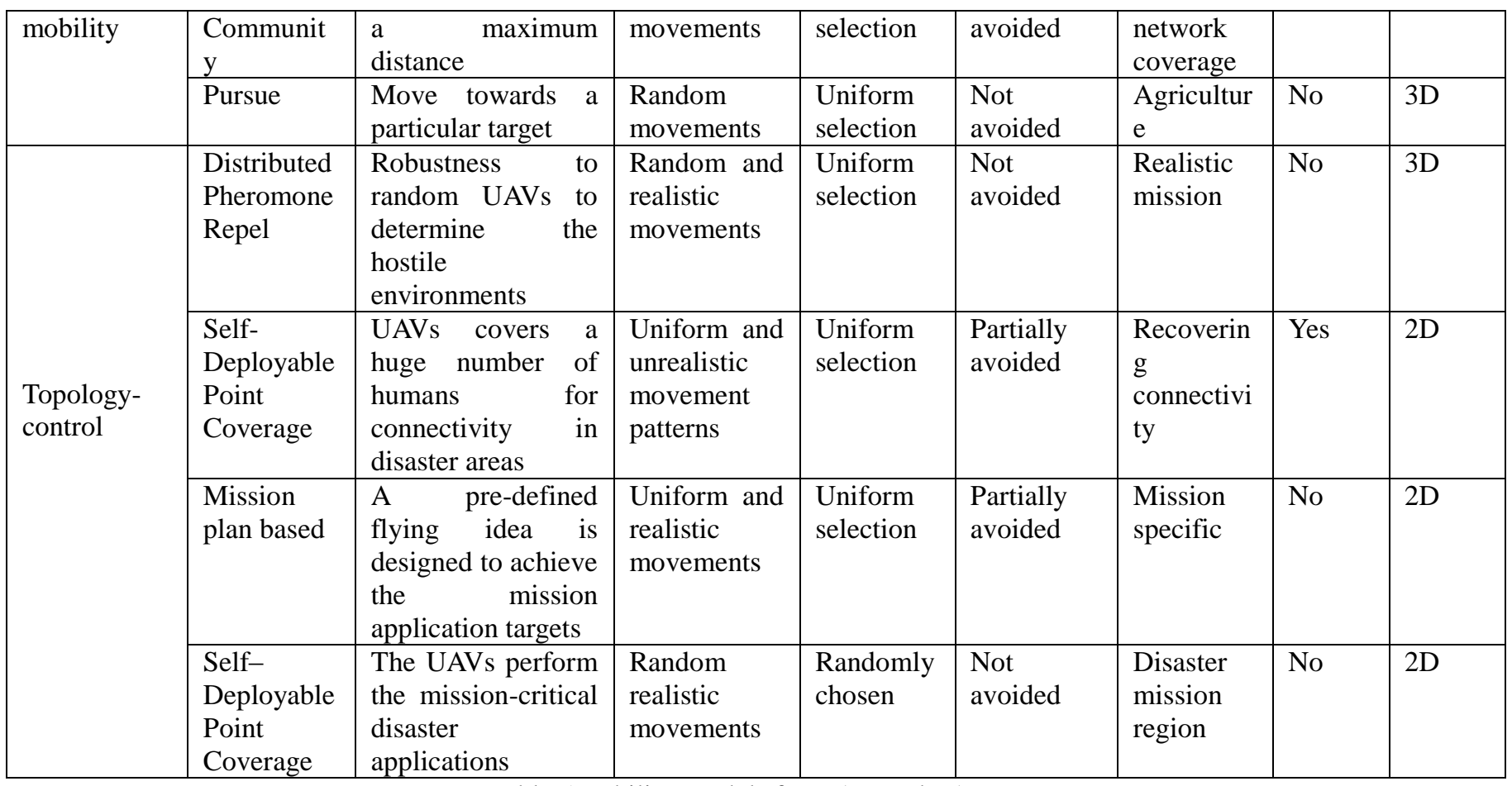

Table 5Mobility Models for UAV and FANET

\begin{tabular}{|c|c|c|c|c|c|}
\hline $\begin{array}{l}\text { Routing } \\
\text { Protocol }\end{array}$ & $\begin{array}{c}\text { Type of Flying } \\
\text { Object }\end{array}$ & Category & Routing Objective & $\begin{array}{c}\text { Mobility } \\
\text { Model }\end{array}$ & Advantages \\
\hline $\begin{array}{l}\text { UAV-Assisted } \\
\text { VANETs } \\
\text { routing } \\
\text { protocol [53] }\end{array}$ & $\begin{array}{l}\text { Mobile flying } \\
\text { vehicles }\end{array}$ & & $\begin{array}{l}\text { To maximize data routing } \\
\text { and connectivity of the } \\
\text { vehicles using UAVs }\end{array}$ & Random walk & $\begin{array}{l}\text { Amplifies the routing } \\
\text { reliability and } \\
\text { connectivity under } \\
\text { sparse vehicle scenario }\end{array}$ \\
\hline $\begin{array}{l}\text { UAV Search } \\
\text { Mission } \\
\text { Protocol } \\
\text { (USMP) [54] }\end{array}$ & Drones & & $\begin{array}{l}\text { To Improves search } \\
\text { performance }\end{array}$ & Random Walk & $\begin{array}{l}\text { Swarming UAVs can } \\
\text { collect data through } \\
\text { routing to locate the } \\
\text { UAV and avoids } \\
\text { explicit location } \\
\text { updates. }\end{array}$ \\
\hline $\begin{array}{l}\text { Geographical } \\
\text { routing on the } \\
\text { Internet of } \\
\text { Drones [55] }\end{array}$ & Drones & & $\begin{array}{l}\text { To analyze the geographic } \\
\text { routing performance on } \\
\text { the internet of drones }\end{array}$ & $\begin{array}{l}\text { Random } \\
\text { model }\end{array}$ & $\begin{array}{l}\text { High } \quad \text { end-to-end } \\
\text { packet delivery ratio }\end{array}$ \\
\hline RLPR [56] & UAV & $\begin{array}{l}\text { Greedy } \\
\text { Routing }\end{array}$ & $\begin{array}{lrr}\text { The relative } & \text { speed, } \\
\text { energy, and } & \text { signal } \\
\text { strength based } & \text { reliable } \\
\text { routing } & & \end{array}$ & $\begin{array}{l}\text { Random } \\
\text { model }\end{array}$ & $\begin{array}{l}\text { Highly reliable under a } \\
\text { highly dynamic } \\
\text { environment }\end{array}$ \\
\hline GPMOR[57] & UAV & $\begin{array}{l}\text { Greedy } \\
\text { Routing }\end{array}$ & $\begin{array}{l}\text { Future movement- } \\
\text { oriented reliable routing }\end{array}$ & Gauss-Markov & $\begin{array}{l}\text { Gaussian Markov } \\
\text { mobility model usage } \\
\text { tends to select an } \\
\text { optimal relay. }\end{array}$ \\
\hline LAROD [58] & UAV & & $\begin{array}{l}\text { To use store-and-carry } \\
\text { forward technique and on } \\
\text { improving }\end{array}$ & $\begin{array}{l}\text { Random and } \\
\text { pheromone } \\
\text { model }\end{array}$ & $\begin{array}{llr}\text { Better delivery ratio } & \text { and less routing } \\
\text { and } & \text { lorhead. } & \\
\text { overhal }\end{array}$ \\
\hline
\end{tabular}




\section{SURVEY ARTICLE}

\begin{tabular}{|c|c|c|c|c|c|}
\hline & & \multirow{5}{*}{$\begin{array}{l}\text { Opportuni } \\
\text { stic } \\
\text { Routing }\end{array}$} & $\begin{array}{l}\text { communication } \\
\text { efficiency. }\end{array}$ & & \\
\hline AeroRP [59] & Test Aircrafts & & $\begin{array}{l}\text { Geographical delay- } \\
\text { tolerant routing protocol }\end{array}$ & $\begin{array}{l}\text { Random } \\
\text { Waypoint }\end{array}$ & $\begin{array}{l}\text { To hold the data } \\
\text { packet, the efficient } \\
\text { next-hops are selected }\end{array}$ \\
\hline XLinGo [60] & $\begin{array}{l}\text { Mobile FANET } \\
\text { Nodes }\end{array}$ & & $\begin{array}{l}\text { To improve } \\
\text { transmission } \\
\text { simultaneous multiple } \\
\text { video flow over }\end{array}$ & $\begin{array}{l}\text { Random } \\
\text { Waypoint }\end{array}$ & $\begin{array}{l}\text { Dynamic Forwarding } \\
\text { Delay is used for } \\
\text { selecting an optimal } \\
\text { relay node. }\end{array}$ \\
\hline LADTR [61] & $\begin{array}{l}\text { Drone and } \\
\text { Ferry UAVs }\end{array}$ & & $\begin{array}{l}\text { It aims to minimize the } \\
\text { data forwarding delay by } \\
\text { introducing ferry UAVs }\end{array}$ & Gauss-Markov & $\begin{array}{l}\text { Enhances the contact } \\
\text { rate between the UAV } \\
\text { nodes in post-disaster } \\
\text { applications }\end{array}$ \\
\hline VDNet [62] & $\begin{array}{l}\text { Quadrotor } \\
\text { Drones }\end{array}$ & & $\begin{array}{l}\text { To guarantee highly } \\
\text { efficient data transmission }\end{array}$ & $\begin{array}{l}\text { Random } \\
\text { model }\end{array}$ & $\begin{array}{l}\text { Maximizes the } \\
\text { efficiency of data } \\
\text { message delivery }\end{array}$ \\
\hline CRUV [63] & Drones & $\begin{array}{l}\text { Greedy } \\
\text { and } \\
\text { opportunis } \\
\text { tic }\end{array}$ & $\begin{array}{l}\text { To find the shortest and } \\
\text { the most reliable routing } \\
\text { paths for message } \\
\text { delivery }\end{array}$ & Random walk & $\begin{array}{l}\text { Enhances the routing } \\
\text { performance by } \\
\text { selecting the UAVs at } \\
\text { intermediate nodes }\end{array}$ \\
\hline ANOR [64] & Small drones & & $\begin{array}{lr}\text { Enhances the } & \text { WSN } \\
\text { routing by } & \text { introducing } \\
\text { opportunistic } & \text { routing } \\
\text { using UAVs } & \end{array}$ & $\begin{array}{l}\text { Multiple UAV } \\
\text { mobility } \\
\text { models }\end{array}$ & $\begin{array}{l}\text { High packet delivery } \\
\text { ratio with minimum } \\
\text { delay }\end{array}$ \\
\hline CORF [65] & Drones & & 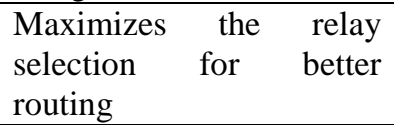 & $\begin{array}{l}\text { Shortest Path } \\
\text { Map-Based } \\
\text { Movement }\end{array}$ & $\begin{array}{l}\text { High message relaying } \\
\text { reliability }\end{array}$ \\
\hline
\end{tabular}

Table 6 Mobility Models Applied to Geographical Routing in UAV and FANET

\subsection{Mobility Models for WSN}

In a general setting, the sensor nodes and sink are stable and static in WSN. The mobility is WSN depends on a specific application environment, and a small set of nodes act as a mobile. Many research efforts have been dedicated to modeling mobile sensor devices with stable and mobile sink [66][67]. Sink mobility potentially leads to a better solution. The MANET mobility models are applied for modeling the movement behavior of sensor devices. However, the sink mobility modeling is different from the mobility models of mobile sensors. The conventional sink mobility models are designed in both controllable and uncontrollable manner. The controllable sink mobility countermeasures the issues of mobility, trajectory design, and sink movement-based routing. Moreover, the manageable sink mobility models are further categorized into the unrestricted model and restricted geographic model. The uncontrollable sink mobility focuses on issues such as location maintenance and routing. Depending on the movement of the mobile sink, the mobility model is further divided into a random and a social mobility model. The current research mainly focuses on random mobility compared to the social mobility models.

Uncontrollable and Controllable Mobility Models: WSN adapts the random mobility models of MANET to model the uncontrollable movement behavior of sensors and sink. A routing technique is essential for the sink location update and data delivery when the sink mobility is uncontrollable. The controllable mobility models shift the focus from dynamic routing decisions to speed control and trajectory design related to different mobility models.

The possibility of pre-scheduling of data reporting and location updating over controllable mobility behavior reduces the challenges of routing protocol design. Once the sink mobility trajectory is defined, the sink traverses along the path for data collection. The adjustment over sink speed based on the sensory data buffering of nearby sensors ensures the best environment monitoring.

Table 7 describes examples of mobility models. On the one hand, the movement speed of the sink and its pause time becomes essential since it is essential to maintain a better tradeoff between data latency and data collection efficiency. Alternatively, trajectory design is another crucial issue. There is a need for a joint solution of data routing and motion control optimization.

Moreover, the routing problem is solved by the one hop, multihop, bounded hop, cluster, theoretical scheduling, and data buffering based routing decision, as discussed in table 8 . 


\section{SURVEY ARTICLE}

\begin{tabular}{|l|l|l|l|l|}
\hline \multicolumn{1}{|c|}{ Schemes } & \multicolumn{1}{|c|}{ Mobility } & \multicolumn{1}{|c|}{ Sub-Type } & \multicolumn{1}{c|}{ Characteristic } & \multicolumn{1}{c|}{ Challenges } \\
\hline $\begin{array}{l}\text { MULE based Simple } \\
\text { Analytical Model [68] and } \\
\text { Zebra Net [69] }\end{array}$ & $\begin{array}{l}\text { Un- } \\
\text { controllable }\end{array}$ & Random & $\begin{array}{l}\text { The movement cannot } \\
\text { be pre-defined }\end{array}$ & $\begin{array}{l}\text { No information on node } \\
\text { location and Routing }\end{array}$ \\
\hline Car Tel and TrainSense [70] & \multirow{2}{*}{$\begin{array}{l}\text { Controllable } \\
\text { Elevator-Assisted Sensor Data }\end{array}$} & $\begin{array}{l}\text { Pre-defined } \\
\text { Path }\end{array}$ & $\begin{array}{l}\text { Nodes move along the } \\
\text { pre-defined path }\end{array}$ & $\begin{array}{l}\text { Speed Control and data } \\
\text { Pollection }\end{array}$ \\
\cline { 1 - 3 } & Location & $\begin{array}{l}\text { Node move along with } \\
\text { a pre-defined set of } \\
\text { locations }\end{array}$ & Trajectory design \\
\cline { 1 - 4 } $\begin{array}{l}\text { Robot Localization [72] and } \\
\text { MiNT-m [73] }\end{array}$ & $\begin{array}{l}\text { Unrestricted } \\
\text { Movement }\end{array}$ & No constraints & $\begin{array}{l}\text { Motion control and } \\
\text { routing }\end{array}$ \\
\hline
\end{tabular}

Table 7 Types and Examples of Mobility Models in WSN

\begin{tabular}{|c|c|c|c|c|c|c|}
\hline Mechanism & $\begin{array}{l}\text { No of } \\
\text { Sinks }\end{array}$ & $\begin{array}{l}\text { Speed/ } \\
\text { Control }\end{array}$ & $\begin{array}{l}\text { Trajec } \\
\text { tory }\end{array}$ & Traffic & Routing & Model \\
\hline Simple Analytical Model [74] & \multirow{5}{*}{ Multiple } & $\begin{array}{l}\text { Slow mobility/ } \\
\text { None }\end{array}$ & None & Dynamic & One Hop & Distributed \\
\hline Energy Efficient Scheme [75] & & mobility/ & Yes & Static & $\begin{array}{l}\text { Theoretical } \\
\text { Scheduling }\end{array}$ & Centralized \\
\hline $\begin{array}{l}\text { Two-Tier Data Dissemination } \\
\text { (TTDD) [76] }\end{array}$ & & mobility/ & None & Dynamic & Grid & Distributed \\
\hline $\begin{array}{l}\text { Hierarchical Cluster-based } \\
\text { Data Dissemination (HCDD) } \\
\text { [77] }\end{array}$ & & mobility/ & None & Dynamic & Cluster & Distributed \\
\hline Data Mules[78] & & mobility/ & None & Dynamic & $\begin{array}{l}\text { Load } \\
\text { Balancing }\end{array}$ & Centralized \\
\hline MILP and GMRE [79] & \multirow{5}{*}{ Single } & mobility/ & None & Dynamic & Shortest & $\begin{array}{l}\text { Centralized and } \\
\text { Distributed }\end{array}$ \\
\hline $\begin{array}{l}\text { Provably Optimal Algorithm } \\
\text { [80] }\end{array}$ & & mobility/ & Yes & Static & $\begin{array}{l}\text { Theoretical } \\
\text { Scheduling }\end{array}$ & Centralized \\
\hline SenCar $[81]$ & & $\begin{array}{l}\text { Slow mobility/ } \\
\text { None }\end{array}$ & Yes & Dynamic & Multi-hop & Centralized \\
\hline $\begin{array}{l}\text { Rendezvous based Approach } \\
\text { [82] }\end{array}$ & & $\begin{array}{l}\text { Slow mobility/ } \\
\text { None }\end{array}$ & Yes & Dynamic & $\begin{array}{l}\text { Data } \\
\text { Buffering }\end{array}$ & Centralized \\
\hline BRH-MDG [83] & & $\begin{array}{l}\text { Slow } \\
\text { mobility/None }\end{array}$ & Yes & Dynamic & $\begin{array}{l}\text { Bounded } \\
\text { Hop }\end{array}$ & Distributed \\
\hline
\end{tabular}

Table 8 Comparison of the Characteristics of Geographical Routing in WSN

\subsubsection{Mobility Models Applied to Geographical Routing in WSN}

The WSN utilizes entity and group mobility models in general. The nodes are located in the known location in modeling WSN, especially in forest monitoring applications. The unknown nodes are dropped from a plane onto the forest, and sensors are appended to animals or humans in the area. The sensor nodes have to get precise location information when the information is collected from several sensors. However, the research conducted on the random mobility models impact on localization is less. In forest monitoring environments, the trajectory of sensor nodes that attach to the animals is irregular. Thus, the random mobility models can mimic the movement behavior of animals in the forest area.
The random mobility model has less memory usage and generates unrealistic movements, including sudden speed and movement direction changes. The mobile nodes follow a restricted movement in the simulation area since it returns to the origin after a specific time. It can reflect the random motion of animals in a forest.

In the second scenario, the sensor nodes are deployed along a river, and the stable sensors are placed on the river banks. To model these sensor networks, the target and path-finding models have been widely used. According to the two-phase process of sensors, such as active and inactive phases, the sensors have to characterize these movement behavior phases. The sensors plan to move to a new location during the inactive phase, either pre-defined or randomly. In the active 


\section{SURVEY ARTICLE}

phase, the sensors need to locate in the same area for a particular time to forward the compressed data to other nodes or sinks. Several path planning algorithms have recently impacted localization since the sensors need to localize themselves to monitor the environment. The static and dynamic path planning models improve the localization performance of WSN. A static path planning model decides the trajectory of sensors in advance. So it is appropriate for regular terrain, whereas the dynamic path decision according to the current situation is more suitable for real-time applications. However, both the path planning models reach the local optimum. However, both have their disadvantages in modeling the sensor networks. The other mobile WSN geographic routing models GRCS [84], Elastic Routing [85], Stability-aware geographic routing in energy-harvesting WSN (EH-WSNs) [86], GRACO [87], and Speed Up-Greedy Perimeter Stateless Routing (SU-GPSR) [88] integrate random mobility models for performance analysis. Finally, the Greedy Maximum Residual Energy (GMRE) [89] uses the controlled mobility pattern. Table 9 provides a comparative analysis of various mobility models over WSN geographic routing protocols.

\begin{tabular}{|c|c|c|c|c|}
\hline Routing Protocol & Category & Routing Objective & Mobility Model & Advantages \\
\hline GRCS [84] & \multirow{6}{*}{$\begin{array}{l}\text { Greedy } \\
\text { Routing }\end{array}$} & $\begin{array}{l}\text { To dynamically optimize } \\
\text { the routing path to the } \\
\text { destination }\end{array}$ & $\begin{array}{l}\text { Random } \\
\text { Waypoint }\end{array}$ & $\begin{array}{l}\text { Cluster and greedy } \\
\text { model reduce the delay }\end{array}$ \\
\hline Elastic Routing [85] & & $\begin{array}{l}\text { Intends to provide superior } \\
\text { support to the mobile sinks }\end{array}$ & $\begin{array}{l}\text { Random } \\
\text { Mobility }\end{array}$ & Energy Efficiency \\
\hline GMRE [89] & & $\begin{array}{l}\text { To offer an entirely } \\
\text { distributed and localized } \\
\text { greedy routing solution for } \\
\text { sink mobility }\end{array}$ & $\begin{array}{l}\text { Controlled } \\
\text { Mobility }\end{array}$ & $\begin{array}{l}\text { Shortest path routing due } \\
\text { to sink mobility }\end{array}$ \\
\hline EH-WSNs [86] & & $\begin{array}{l}\text { To provide an unlimited } \\
\text { network lifetime and } \\
\text { reliable routes selection }\end{array}$ & Random model & $\begin{array}{l}\text { Reliable maximum } \\
\text { speed data transmission }\end{array}$ \\
\hline GRACO [87] & & $\begin{array}{l}\text { Reliable data delivery by } \\
\text { adjusting the blocking } \\
\text { situation }\end{array}$ & Random model & $\begin{array}{l}\text { Avoid void holes and } \\
\text { quick data delivery }\end{array}$ \\
\hline SU-GPSR [88] & & $\begin{array}{l}\text { To reduce the hop count of } \\
\text { routes by selecting the } \\
\text { density of nodes }\end{array}$ & Random & $\begin{array}{l}\text { Minimizes the number of } \\
\text { hops without } \\
\text { compromising the QoS } \\
\text { of routing }\end{array}$ \\
\hline
\end{tabular}

Table 9 Mobility Models Applied to Geographical Routing Techniques over WSNs

\subsection{Mobility Models for UWSN}

Like ground WSN, the UWSN comprises different sensor nodes that can collaboratively monitor the specific oceanic environment. The information gathered from UWSN nodes is forwarded to a static or mobile surface station. In the UWSN environment, diverse factors affect the sensor node's mobility pattern, speed, and direction compared with ground WSN. In the ground WSN, the sensor nodes are mostly static, and the mobility of ground WSN sensors is much lower than the UWSN sensors. In UWSN, the temperature, wind, and power of water significantly influence sensor node mobility. Thus, it poses significant challenges in geographic routing the packets over the UWSN environment. The fundamental WSN routing protocols are mostly designed for ground WSN, and such protocols lack to attain nearly realistic performance in UWSN. A few UWSN routing protocols consider the realistic mobility patterns of underwater and test in a real-time environment. Generally, UWSN specific mobility models relatively lack groundwork. For UWSN simulation, the stochastic WMN mobility models are used. A well-known random walk and random walkway point mobility models are mostly considered in simulating the UWSN routing protocols. A Meandering Current Mobility (MCM) model is designed for UWSNs, whereas it lacks to consider the current changes with depth and routing efficiency over time [90]. A restricted mobility model [91] has been introduced to compute the ocean depth in which the mobile nodes move with limited mobility over a floating regime. The restricted mobility model of Restricted Float Sensor (RFS) offers dynamism among static and mobile WMNs. However, the RFS does not consider the realistic mobility patterns of UWSN nodes presented in various depth areas in which the routing efficiency is affected by the water power of the ocean. Moreover, it is crucial to develop mobility models that consider the characteristics of UWSN for attaining enhanced routing performance in UWSN specific applications. The UWSN is a proliferated network, and only a limited number of mobility models are introduced for UWSNs. 


\section{SURVEY ARTICLE}

\subsubsection{Mobility Models Applied to Geographical Routing in} UWSN

Unlike WSN, the nodes in UWSN are mobile, and they approximately move with $2-3 \mathrm{~m} / \mathrm{sec}$ speed to monitor the various activities of underwater circumstances. The performance of UWSN routing protocols is dramatically minimized according to the effect of the realistic movements of underwater sensors. A practical mobility model can realistically reflect the accurate movements of underwater sensor nodes with ocean currents. The random and MCM mobility models are familiarly used in UWSN. In table 16, the Vector-based forwarding (VBF) [92], Hop by Hop VBF (HHVBF) [93], Reliable and Energy Balanced Algorithm Routing
(REBAR) [94], Directional Flooding based Routing (DFR) [95], LCAD [96], and Totally Opportunistic Routing Algorithm (TORA) [97] exploit fundamental random mobility models. The Sector-Based Routing with Destination Location Prediction (SBR-DLP) [98] and Depth-Controlled Routing protocol (DCR) [99] utilize pre-planned movement and vertical movement trajectories for evaluation, respectively. Further, the Stateless Opportunistic Routing Protocol (SORP) [100], Void Aware Pressure Routing (VAPR) [101], and GEographic and opportunistic routing with Depth Adjustment-based topology control for communication Recovery (GEDAR) [102] use MCM mobility model. Table 10 discusses the different mobility models applied to geographical routing in UWSNs.

\begin{tabular}{|c|c|c|c|c|}
\hline Routing Protocol & Category & Routing Objective & $\begin{array}{l}\text { Mobility } \\
\text { Model }\end{array}$ & Advantages \\
\hline VBF [92] & \multirow{3}{*}{$\begin{array}{l}\text { Greedy } \\
\text { Routing }\end{array}$} & $\begin{array}{l}\text { Selecting eligible node } \\
\text { with Cartesian routing } \\
\text { for packet forwarding }\end{array}$ & $\begin{array}{l}\text { Random } \\
\text { walk }\end{array}$ & $\begin{array}{l}\text { Less energy consumption } \\
\text { and reliable router selection }\end{array}$ \\
\hline HH-VBF [93] & & $\begin{array}{l}\text { Designing hop by hop } \\
\text { unique virtual pipe } \\
\text { routing }\end{array}$ & $\begin{array}{l}\text { Random } \\
\text { model }\end{array}$ & $\begin{array}{l}\text { Duplicate packet reduction } \\
\text { and less energy consumption }\end{array}$ \\
\hline REBAR [94] & & $\begin{array}{l}\text { To optimize energy } \\
\text { consumption, improve } \\
\text { packet delivery ratio, } \\
\text { and handle void area }\end{array}$ & $\begin{array}{l}\text { Random } \\
\text { movement }\end{array}$ & $\begin{array}{l}\text { High scalability and Void } \\
\text { handling }\end{array}$ \\
\hline DFR [95] & \multirow{2}{*}{$\begin{array}{l}\text { Face } \\
\text { Routing }\end{array}$} & $\begin{array}{l}\text { Optimized } r \text { data } \\
\text { forwarding } \text { strategy by } \\
\text { selecting high-quality } \\
\text { links }\end{array}$ & $\begin{array}{l}\text { Random } \\
\text { movement }\end{array}$ & Void handling \\
\hline SBR-DLP [98] & & $\begin{array}{l}\text { Predicts the location of } \\
\text { destination for efficient } \\
\text { data transmission }\end{array}$ & $\begin{array}{l}\text { Pre-planned } \\
\text { movement }\end{array}$ & $\begin{array}{l}\text { Pre-planned movements } \\
\text { based on destination location } \\
\text { prediction }\end{array}$ \\
\hline LCAD [96] & $\begin{array}{l}\text { Greedy- } \\
\text { Face- } \\
\text { Greedy }\end{array}$ & $\begin{array}{l}\text { Cluster-based two-level } \\
\text { communication }\end{array}$ & Random & Medium scalability \\
\hline SORP [100] & \multirow{3}{*}{$\begin{array}{l}\text { Opportuni } \\
\text { stic } \\
\text { Routing }\end{array}$} & $\begin{array}{l}\text { Aims to detect void } \\
\text { area and trapped nodes }\end{array}$ & $\mathrm{MCM}$ & $\begin{array}{l}\text { Minimum energy } \\
\text { consumption, packet loss, } \\
\text { and end-to-end delay }\end{array}$ \\
\hline TORA [97] & & $\begin{array}{lr}\text { To avoid } & \text { horizontal } \\
\text { transmission } & \text { and } \\
\text { prolong the } & \text { network } \\
\text { lifetime } & \\
\end{array}$ & $\begin{array}{l}\text { Random } \\
\text { walk }\end{array}$ & $\begin{array}{lr}\text { Void handling } & \text { and } \\
\text { Optimized } & \text { energy } \\
\text { consumption }\end{array}$ \\
\hline VAPR [101] & & $\begin{array}{l}\text { To set up each node's } \\
\text { next-hop direction } \\
\text { based on surface } \\
\text { reachability information }\end{array}$ & MCM & $\begin{array}{lr}\text { Guarantees } & \text { packet delivery } \\
\text { with the } & \text { support of } \\
\text { opportunistic } & \text { directional } \\
\text { forwarding } & \end{array}$ \\
\hline
\end{tabular}




\section{SURVEY ARTICLE}

\begin{tabular}{|l|l|l|l|l|}
\hline DCR [99] & $\begin{array}{l}\text { To enhance the routing } \\
\text { efficiency by adjusting } \\
\text { the depth level of nodes }\end{array}$ & $\begin{array}{l}\text { Vertical } \\
\text { movement }\end{array}$ & $\begin{array}{l}\text { Drastically reduces the void } \\
\text { regions and improves the } \\
\text { data delivery }\end{array}$ \\
\hline GEDAR [102] & $\begin{array}{l}\text { Greedy } \\
\text { opportunis } \\
\text { tic }\end{array}$ & $\begin{array}{l}\text { To handle the void } \\
\text { issues by moving the } \\
\text { nodes to an in-depth } \\
\text { area by adjusting the } \\
\text { topology }\end{array}$ & $\begin{array}{l}\text { Optimal next-hop selection } \\
\text { and high packet delivery } \\
\text { ratio }\end{array}$ \\
\hline
\end{tabular}

Table 10 Mobility Models Applied to Geographical Routing in UWSNs

\subsection{Mobility Models for VANET}

The most significant component in simulating the VANET routing protocol is the mobility model, as the mobility models in VANET mimic traffic behavior on the road. It is essential to employ realistic mobility patterns in simulation to reflect the real-time VANET performance [16]. The inherent restriction of vehicle mobility on a road topology is a significant implication of VANET mobility models. Conventionally, VANET has used some specific mobility models like a random pattern; graph constrained mobility models. However, these models do not reflect road traffic behavior realistically due to the ignorance of road intersection, traffic lights, speed acceleration and deceleration regarding neighbor vehicles, and driver behavior such as overtaking and lane changing. The realistic VANET mobility models should incorporate realistic topological maps that reflect the diverse road densities and various streets with diverse speed limits. Consequently, roadside obstacles are another critical parameter in designing the VANET mobility model. The mobility models of VANET have been classified into macroscopic, microscopic, and mesoscopic models. Macroscopic models deal with vehicle distribution modeling, whereas the microscopic model considers the vehicle position, speed, and acceleration. Moreover, the mesoscopic models apply aggregation over the movements of different nodes.

Random-based Mobility Model: The random models are simple mobility model proposed for multihop wireless networks. In such type, the mobility parameters such as node speed and destination point are randomly selected in the simulation. The familiar random VANET mobility models are random waypoint, reference point group, freeway, Manhattan, car flow, and intelligent driver models. However, the random models are inappropriate for the vehicular environment, as they lack to reflect the realistic vehicular characteristics such as real-time road map and others that have a high impact on the VANET routing performance. The random mobility models of VANET have been classified into microscopic and macroscopic. Macroscopic models deal with vehicle distribution modeling, whereas the microscopic model considers the vehicle position, speed, and acceleration. Compared to the macro mobility models, the microscopic models are suitable for modeling the VANET topology.
Flow-based Mobility Model: The flow-based models utilize a probability density function to model the movement patterns of a single vehicle or group of vehicles. The group of mobility models is further categorized into macroscopic and mesoscopic. The macroscopic models handle the vehicle distribution functions, and the mesoscopic models apply aggregation over the movements of different nodes. The gas kinetic traffic model is an example of mesoscopic models. Moreover, the mesoscopic models are highly fit to model the VANET environment than the macroscopic models.

Traffic-based Mobility Model: The traffic models exploit the real-time traffic situation such as intersection points, traffic lights, and other traffic rules in modeling the movements of vehicles. The traffic model highly deviates from the flow model, as the flow model considers the intersections and traffic lights as obstacles during modeling. Unlike the flow model, the traffic model considers the realistic traffic characteristics in the movement path design of vehicles. Further, the traffic model is categorized into agentcentric and flow-centric. The agent-centric model constructs a distinct path to every vehicle, whereas the flow-centric model creates a subset of paths for vehicles. The agent-centric models are highly efficient than the flow-centric models due to their less complexity.

Behavioral-based Mobility Model: Generally, the drivers are humans in real-time VANET, and they cannot follow the same behavior during driving. The drivers change their driving characteristics based on the local VANET parameters. The behavioral-based models consider the behavior factors that influence the driver's decision-making during the movement path design.

Trace-based Mobility Model: Instead of developing complex movement patterns, the trace-based models trace the realistic movement of vehicles. By extracting the original mobility traces from a real-time VANET environment and maximizing efficiency, trace models have been highly employed in recent days. Moreover, the trace-based models achieve proper realism during the simulation.

Based on the scope functions and characteristics, the VANET mobility models are segregated into five main categories: random-based, flow-based, traffic-based, behavioral-based, 


\section{SURVEY ARTICLE}

and trace-based, as depicted in table 11. The random waypoint is a simple model that allows the mobile nodes to move freely in the network without any limitations. However, sudden speed and direction changes turn problems in modeling the vehicle's movement behavior on the road. A node could not wholly follow the random mobility model in real-time, but the node mobility can be predictable. Some specific tools are designed for VANET to generate controllable movement on the road. For example, the macroscopic MObility model generator for the VEhicular ad hoc network (MOVE) makes realistic mobility models in VANET. The visualization and trace property of MOVE shows and traces the movement

\begin{tabular}{|c|c|c|c|c|}
\hline Type & Subtype & Examples & Interaction Level & Suitable Scenario \\
\hline \multirow[t]{2}{*}{ Random } & Microscopic & $\begin{array}{c}\text { RWM, RPGM, Freeway } \\
\text { Model }\end{array}$ & \multirow[t]{2}{*}{ No } & \multirow[t]{2}{*}{$\begin{array}{l}\text { Safety and comfort } \\
\text { traveling }\end{array}$} \\
\hline & Macroscopic & CFM, IDM, CA Model & & \\
\hline \multirow{2}{*}{ Flow [16] } & Macroscopic Flow & LWR Model & \multirow{2}{*}{ Small } & \multirow{2}{*}{$\begin{array}{l}\text { Safety and traffic } \\
\text { applications }\end{array}$} \\
\hline & Mesoscopic Flow & $\begin{array}{l}\text { The gas kinetic traffic } \\
\text { flow model }\end{array}$ & & \\
\hline Traffic [103] & No & SUMO and CORSIM & Real & Traffic and safety \\
\hline Behavioral [104] & No & Balmer Model & Real & Traffic and comfort \\
\hline Trace Based [105] & No & $\begin{array}{c}\text { UDel Model, MMTS } \\
\text { Model }\end{array}$ & Real & Safety and Comfort \\
\hline
\end{tabular}

Table 11 Characteristics of Mobility Models in VANET

\subsubsection{Mobility Models Applied for Geographical Routing in VANET}

Vehicular communication becomes essential in the intelligent transport system, and it is used in applications from safety to easy travel on the road. The physical motion of vehicle characteristics is mostly emulated by the mobility models under the category of motion. Vehicular communication includes vehicle-to-infrastructure and vehicle-to-vehicle communication. These communications are involved in travel time prediction, information dissemination, and congestion management. According to the road map topology, the mobility models should emulate the vehicle movement along a road, speed changes, movement in a direction, and stops at traffic signals. In the design of vehicle movement behavior, mostly the vehicles move along the shortest trajectory on the road. The trace-based mobility models collect the mobility traces and extract the mobility patterns of vehicles. The trace analysis assists in capturing the daily life movement of humans using vehicles on the road. Moreover, the movement of vehicles and their stay time at a given location depends on the time.

Nowadays, complex road models are another issue in VANET communication. It is challenging to model the road topology with traffic signs, signals, and obstacles such as bridges and behavior of vehicle nodes on the road. This mobility generator tool works with the micro simulator traffic model, named SUMO. The MOVE includes the road map and vehicle movement editor. By creating and editing the road map topology automatically or manually using the map editor, the MOVE generates the simulation model nearly equal to the real-time scenario. The vehicle movement editor traces the movement, and the micro-mobility features model the singlevehicle behavior based on the neighboring vehicles. This feature leads the MOVE to model a more realistic road topology with vehicle movement behavior. overpasses. For instance, the STreet RAndom Waypoint (STRAW) [106] considers the complex intersections, traffic signs, and signals for modeling the VANET topology. The trajectory design considering the mobility parameters alone cannot emulate the real-time vehicle movement behavior on the road. However, it cannot meet specific QoS requirements like drivers' dynamic decisions based on road topology. The fuzzy-assisted social-based routing (FAST) protocol [107] considers the social behavior of drivers on the road. The usage of global knowledge is essential for building vehicular traffic information that takes critical mobility decisions at intersections. The Vehicle-Assisted Data Delivery (VADD) [108] exploits a real street map to derive the street layout and route selection. The Prediction-based Soft Routing Protocol (PSR) [109] collects mobility traces from more than 4,000 taxies in Shanghai over six months and identifies the Vehicular Mobility Pattern (VMP) Markov model scheme. Adaptation of mobility models to geographical routing over VANETs is discussed in table 18. Different type of VANET geographic routing protocols utilizes diverse mobility models for evaluation. For example, the GPCR [110], A-STAR [111], and GyTAR [112] employ macro, M-grid, and proprietary mobility models, respectively. The works like CAR [113] and Greedy Routing with Abstract Neighbor Table (GRANT) [114] use the car mobility model. Further, the trace-based, 


\section{SURVEY ARTICLE}

obstacle based, stochastic, and Manhattan mobility models are employed in Distance-Vector-Based Recovery-Strategy (PBR-DV) [115], Junction-Based Routing (JBR) [116], VADD [108], and Opportunity routing protocol for data forwarding based on vehicle mobility Association (OVMA) [117] respectively. Further, simple random models are utilized in GeOpps [118], Hybrid opportunistic, and positionbased routing protocol [119]. Moreover, the realistic mobility patterns are widely exploited in most of the VANET geographic routing protocols like LOUVRE [120], Location and Direction Aware Opportunistic Routing (LDAOR) [121], SCAOR [122], Probability prediction-based reliable and efficient opportunistic routing (PRO) [123], and 3-Parameter Routing Cost Function based opportunistic routing [124]. Table 12 illustrates the mobility models applied to VANETs.

\begin{tabular}{|c|c|c|c|c|}
\hline Routing Protocol & Category & Routing Objective & $\begin{array}{l}\text { Mobility } \\
\text { Model }\end{array}$ & Advantages \\
\hline GPCR [110] & \multirow{8}{*}{ Greedy } & $\begin{array}{l}\text { To improves the recovery strategy } \\
\text { of geographic forwarding } \\
\text { algorithms }\end{array}$ & $\begin{array}{l}\text { Macro mobility } \\
\text { Model }\end{array}$ & $\begin{array}{l}\text { It can suppress the graph } \\
\text { planarization issues }\end{array}$ \\
\hline CAR [113] & & $\begin{array}{l}\text { Routing protocol for inter-vehicle } \\
\text { communication to provide } \\
\text { scalability with low overhead }\end{array}$ & $\begin{array}{l}\text { Car mobility } \\
\text { model }\end{array}$ & Error Recovery process \\
\hline LOUVRE [120] & & $\begin{array}{l}\text { To provide guaranteeing a correct } \\
\text { delivery of each packet }\end{array}$ & $\begin{array}{l}\text { Realistic } \\
\text { mobility model }\end{array}$ & $\begin{array}{l}\text { Less delay over Overlay } \\
\text { routes }\end{array}$ \\
\hline A-STAR [111] & & $\begin{array}{l}\text { Packet delivery based on anchor } \\
\text { path with high connectivity }\end{array}$ & $\begin{array}{l}\text { M-Grid } \\
\text { Mobility Model }\end{array}$ & $\begin{array}{l}\text { Suitable for city traffic } \\
\text { environment }\end{array}$ \\
\hline GyTAR [112] & & $\begin{array}{l}\text { Robust route evaluation based on } \\
\text { intersection geographic routing }\end{array}$ & $\begin{array}{l}\text { Proprietary } \\
\text { Model }\end{array}$ & $\begin{array}{l}\text { Intersection usage in } \\
\text { mobility behavior decision }\end{array}$ \\
\hline GRANT [114] & & $\begin{array}{l}\text { To select the best route by } \\
\text { avoiding local maximum }\end{array}$ & $\begin{array}{l}\text { Car mobility } \\
\text { model }\end{array}$ & $\begin{array}{ll}\text { Minimum } & \text { network } \\
\text { overhead } & \end{array}$ \\
\hline PBR-DV [115] & & $\begin{array}{l}\text { Exploits the advantage of greedy } \\
\text { and ad hoc on-demand routing }\end{array}$ & Trace based & Local maximum avoidance \\
\hline JBR [116] & & $\begin{array}{l}\text { It aims to enhance the routing } \\
\text { performance by utilizing the } \\
\text { greedy junction vehicles }\end{array}$ & $\begin{array}{l}\text { Obstacle } \\
\text { Mobility Model }\end{array}$ & $\begin{array}{l}\text { No need for an extra } \\
\text { beacon message }\end{array}$ \\
\hline GeOpps [118] & \multirow{7}{*}{$\begin{array}{l}\text { Opportuni } \\
\text { stic }\end{array}$} & $\begin{array}{l}\text { To efficiently select the next } \\
\text { packet carrier }\end{array}$ & $\begin{array}{l}\text { Random } \\
\text { Mobility Model }\end{array}$ & Reliable Data Delivery \\
\hline VADD [108] & & $\begin{array}{l}\text { To forward the packets with } \\
\text { minimum delay }\end{array}$ & $\begin{array}{l}\text { Stochastic } \\
\text { mobility model }\end{array}$ & $\begin{array}{l}\text { Emulating a realistic city } \\
\text { environment }\end{array}$ \\
\hline OVMA [117] & & $\begin{array}{l}\text { Optimizes the routing efficiency } \\
\text { by making routing decisions } \\
\text { based on the vehicle density }\end{array}$ & $\begin{array}{l}\text { Manhattan } \\
\text { Mobility Model }\end{array}$ & $\begin{array}{lr}\text { Amplified } & \text { routing } \\
\text { efficiency } & \text { extended } \\
\text { network lifetime } & \end{array}$ \\
\hline LDAOR [121] & & $\begin{array}{l}\text { To select the best routers by } \\
\text { taking into account multiple } \\
\text { influencing factors }\end{array}$ & $\begin{array}{l}\text { Map-based } \\
\text { movements }\end{array}$ & $\begin{array}{l}\text { High data delivery rate with } \\
\text { minimum overhead }\end{array}$ \\
\hline SCAOR [122] & & $\begin{array}{l}\text { To alleviate collisions and } \\
\text { improve the efficiency of routing }\end{array}$ & $\begin{array}{l}\text { Realistic } \\
\text { movement } \\
\text { patterns }\end{array}$ & $\begin{array}{l}\text { Improves the packet } \\
\text { delivery ratio and reduces } \\
\text { the collision probability }\end{array}$ \\
\hline PRO [123] & & $\begin{array}{l}\text { To select the best relaying set } \\
\text { based on a relaying probability } \\
\text { prediction value }\end{array}$ & Realistic & $\begin{array}{l}\text { High network throughput } \\
\text { with minimum delay }\end{array}$ \\
\hline $\begin{array}{l}\text { 3-Parameter } \\
\text { Routing [124] }\end{array}$ & & $\begin{array}{l}\text { To propose a new measure } \\
\text { designed using multiple } \\
\text { parameters for candidate set } \\
\text { selection }\end{array}$ & $\begin{array}{l}\text { Real vehicle } \\
\text { movement } \\
\text { patterns }\end{array}$ & $\begin{array}{l}\text { Best forwarding node } \\
\text { selection maximizes the } \\
\text { opportunistic routing } \\
\text { performance }\end{array}$ \\
\hline
\end{tabular}




\section{SURVEY ARTICLE}

\begin{tabular}{|l|l|l|l|l|}
\hline $\begin{array}{l}\text { Hybrid } \\
\text { opportunistic } \\
\text { routing protocol } \\
{[119]}\end{array}$ & $\begin{array}{l}\text { Greedy } \\
\text { and } \\
\text { opportunis } \\
\text { tic }\end{array}$ & $\begin{array}{l}\text { Selecting optimal routers using } \\
\text { the greedy and opportunistic } \\
\text { routing combination }\end{array}$ & $\begin{array}{l}\text { Random } \\
\text { direction }\end{array}$ & $\begin{array}{l}\text { Routing process effectively } \\
\text { removes the expired nodes }\end{array}$ \\
\hline
\end{tabular}

Table 12 Mobility Models Applied to Geographical Routing Techniques in VANETs

\subsection{Mobility Models for DTN}

The nodes in DTNs deliver the data among a sourcedestination pair through mobile relay nodes that opportunistically forward data using a store and carry forward mechanism. In DTNs, the movements of mobile nodes significantly impact the real-time routing performance. Generally, the DTNs are used for real-time applications, and it is difficult to analyze the realistic performance of DTN protocols. Before implementing real-world applications, the DTN routing performance is estimated using a simulator with diverse mobility models. For an accurate evaluation, the mobility models can reflect the real-time movement patterns of mobile nodes [125]. Many conventional mobility models designed for WMNs are widely exploited for assisting the most straightforward DTN protocol evaluation [126]. Such conventional mobility models incorporate some significant mobility characteristics, whereas they lack to capture the realistic movements of nodes in different DTN applications, resulting in reduced routing performance. The DTN mobility models are mainly classified into four types: random mobility models, map-constrained mobility models, social mobility models, and composite mobility models [127]. The DTN mobility models are analyzed in table 13 .

\begin{tabular}{|c|c|c|c|c|c|}
\hline Mobility Models & Type & $\begin{array}{c}\text { Movement } \\
\text { Pattern }\end{array}$ & $\begin{array}{c}\text { Pause } \\
\text { Time }\end{array}$ & Speed & Direction \\
\hline Random Waypoint & \multirow{4}{*}{$\begin{array}{l}\text { Random mobility } \\
\text { models }\end{array}$} & $\begin{array}{l}\text { Random and } \\
\text { unrealistic }\end{array}$ & No & Random & Random \\
\hline $\begin{array}{ll}\text { Random } & \text { Walkway } \\
\text { Point } & \\
\end{array}$ & & Random & Yes & Uniform & Uniform \\
\hline Random Direction & & Random & Yes & Random & Random \\
\hline Levy Walks & & Realistic & Yes & Uniform & Uniform \\
\hline Map-Based & \multirow{4}{*}{$\begin{array}{l}\text { Map-constrained } \\
\text { mobility models }\end{array}$} & Random & Yes & Uniform & Uniform \\
\hline Shortest Path-Based & & Random & Yes & Uniform & Uniform \\
\hline Route-Based Map & & Random & Yes & Uniform & Uniform \\
\hline Manhattan & & Random & Yes & Uniform & Uniform \\
\hline Community-Based & \multirow{4}{*}{$\begin{array}{l}\text { Social mobility } \\
\text { models }\end{array}$} & $\begin{array}{l}\text { Based on social } \\
\text { activities }\end{array}$ & Yes & Uniform & $\begin{array}{l}\text { Intrinsic derived } \\
\text { from the target }\end{array}$ \\
\hline $\begin{array}{l}\text { Time-Variant } \\
\text { Community }\end{array}$ & & $\begin{array}{ll}\text { Based } & \text { on } \\
\text { position } & \\
\text { preference } & \end{array}$ & Yes & Uniform & Uniform \\
\hline $\begin{array}{ll}\text { Working } & \text { Day } \\
\text { Movement } & \end{array}$ & & $\begin{array}{lr}\text { Based } & \text { on } \\
\text { routine } & \text { day } \\
\text { activities } & \end{array}$ & Yes & Uniform & Uniform \\
\hline General Social & & $\begin{array}{l}\text { Based on social } \\
\text { activities }\end{array}$ & Yes & Uniform & Uniform \\
\hline $\begin{array}{l}\text { Self-similar } \quad \text { Least- } \\
\text { Action Walk }\end{array}$ & \multirow{4}{*}{$\begin{array}{l}\text { Composite } \\
\text { mobility models }\end{array}$} & $\begin{array}{l}\text { Based on } \\
\text { Individual walk }\end{array}$ & Yes & $\begin{array}{l}\text { Intrinsic derived } \\
\text { from the target }\end{array}$ & Uniform \\
\hline Post-Disaster Mobility & & $\begin{array}{l}\text { Based on the } \\
\text { specific part of } \\
\text { the city }\end{array}$ & Yes & Uniform & Uniform \\
\hline $\begin{array}{l}\text { Localized Random } \\
\text { Walk }\end{array}$ & & Local based & Yes & Uniform & Uniform \\
\hline Contact Graph & & Correlated & Yes & Uniform & Uniform \\
\hline
\end{tabular}

Table 13 Analysis of Various DTN Mobility Models 


\section{SURVEY ARTICLE}

The random walk mobility models are highly suitable for simple routing protocols designed based on distance and time, as they generate random mobility patterns using the Brownian motion model. The RWP mobility model is utilized to study the simulation performance of DTN protocols. It provides flexibility to produce realistic mobility patterns like human movements in real-time. The disadvantage of a random walkway point is that the node moves along a straight line until selecting the next destination. The random direction avoids the issues in random walkway points. The levy walk model estimates the movement lengths based on power-law distribution. The map-based mobility models reflect the mobility pattern of the practical trace environment and attain high performance in the simulation. The social and composite-based mobility models include the human movement characteristics over a particular region, such as conferences, museums, and others. Such a model improves

\begin{tabular}{|c|c|c|c|c|}
\hline Mobility Model & $\begin{array}{l}\text { Mobility } \\
\text { Type }\end{array}$ & Description & Advantages & Applications \\
\hline WDM [128] & \multirow{3}{*}{ Map-based } & $\begin{array}{l}\text { Produce contact and inter contact } \\
\text { time distributions }\end{array}$ & $\begin{array}{ll}\text { Incorporating } & \text { some } \\
\text { sense of hierarchy } & \\
\end{array}$ & DTN \\
\hline ADMM [129] & & $\begin{array}{l}\text { NHTS about US department and } \\
\text { Transportation }\end{array}$ & $\begin{array}{l}\text { Modeling social } \\
\text { activities and geographic } \\
\text { locations of humans }\end{array}$ & DTN \\
\hline SAME [130] & & $\begin{array}{l}\begin{array}{l}\text { Customizing student habits on } \\
\text { campus }\end{array} \\
\end{array}$ & $\begin{array}{l}\text { Sub model based } \\
\text { movement description }\end{array}$ & DTN \\
\hline SOLAR [131] & \multirow{3}{*}{$\begin{array}{l}\text { Location- } \\
\text { based }\end{array}$} & $\begin{array}{l}\text { The deterministic orbital } \\
\text { movement pattern of mobile users }\end{array}$ & $\begin{array}{l}\text { Human movement } \\
\text { prediction }\end{array}$ & DTN-MANET \\
\hline TVCM [132] & & $\begin{array}{l}\text { Observe the mobility properties } \\
\text { from daily lives to capture the } \\
\text { effective }\end{array}$ & $\begin{array}{l}\text { Skewed location } \\
\text { preference and reappear } \\
\text { measurement }\end{array}$ & DTN \\
\hline SLAW [133] & & $\begin{array}{l}\text { Fractional Gaussian noise based } \\
\text { movement prediction }\end{array}$ & $\begin{array}{l}\text { Individual walker based } \\
\text { movement restrictions }\end{array}$ & DTN \\
\hline HCMM [134] & \multirow{2}{*}{$\begin{array}{l}\text { Community- } \\
\text { based }\end{array}$} & $\begin{array}{l}\text { Probability-based movement } \\
\text { prediction }\end{array}$ & $\begin{array}{l}\text { Home cell movement } \\
\text { predictions }\end{array}$ & DTN \\
\hline ECMM [135] & & Introducing pause time & $\begin{array}{l}\text { Group mobility } \\
\text { encouragement }\end{array}$ & $\begin{array}{l}\text { Mobile social } \\
\text { network-based } \\
\text { DTN }\end{array}$ \\
\hline SIMPS [136] & \multirow[t]{3}{*}{ Sociological } & $\begin{array}{l}\text { Feedback based movement } \\
\text { decision making }\end{array}$ & $\begin{array}{l}\text { Balances the } \\
\text { the volume of current } \\
\text { social interactions }\end{array}$ & DTN \\
\hline GeSoMo [137] & & $\begin{array}{l}\text { Social network-based mobility } \\
\text { traces }\end{array}$ & $\begin{array}{l}\text { Reflect the social } \\
\text { relations of humans }\end{array}$ & DTN \\
\hline SSBMM [138] & & $\begin{array}{l}\text { The daily routine of student's } \\
\text { mobility prediction }\end{array}$ & $\begin{array}{l}\text { Taking into account the } \\
\text { mandatory part of life }\end{array}$ & DTN-MANET \\
\hline
\end{tabular}

Table 14 Adaptation of Various Mobility Models in DTNs

\subsubsection{Mobility Models Applied to Geographical Routing in DTN}

Several geographic-based routing methods are introduced for DTNs. Some of the models consider the heterogeneous node movement patterns in designing the DTN mobility models. The mobility models play a significant role in DTN protocol mobility prediction accuracy and DTN protocol performance in the simulation. The working day movement (WDM) [128], Agenda driven mobility model (ADMM) [129], and SAME [130] are map-based mobility models. Consequently, Sociological orbit aware location approximation and routing (SOLAR) [131], Time-variant community model (TVCM) [132], and Self-Similar Least Action Walk (SLAW) [133] are location-based mobility models. Further, the Home cell community mobility model (HCMM) [134] and the Enhance community mobility model (ECMM) [135] are examples of community-based mobility models. Finally, the sociological mobility models are Sociological interaction mobility for population simulation (SIMPS) [136], GeSoMo [137], and Students Social Based Mobility Model (SSBMM) [138]. Table 14 shows the adaptation of various mobility models to DTN. 


\section{SURVEY ARTICLE}

social group, and it is crucial to adopt the movements of humans in the mobility model design. The map-based mobility models are improved types of fundamental random models that select destinations randomly. Such a model integrates the movements of buses and trains, and it cannot evaluate human mobility patterns. The community mobility models include diverse social model characteristics and

\begin{tabular}{|c|c|c|c|}
\hline Routing Protocol & Routing Objective & Mobility Model & Advantages \\
\hline Vector Routing [139] & $\begin{array}{l}\text { Utilizing the vector of node } \\
\text { movements }\end{array}$ & $\begin{array}{l}\text { Random Waypoint } \\
\text { and Manhattan }\end{array}$ & Improve routing efficiency \\
\hline DGR [140] & $\begin{array}{l}\text { Reduce false routing } \text { decisions } \\
\text { due to inefficient moving } \\
\text { direction }\end{array}$ & Random Waypoint & $\begin{array}{l}\text { Solves the local maximum } \\
\text { problem }\end{array}$ \\
\hline HVR [141] & $\begin{array}{llr}\text { Predicting } & \text { the } & \text { destination } \\
\text { location } & \text { using } & \text { history } \\
\text { information } & & \end{array}$ & $\begin{array}{l}\text { Random Waypoint } \\
\text { and Manhattan }\end{array}$ & Accurate data Forwarding \\
\hline GSaR [142] & Spray based geographic routing & Random Waypoint & $\begin{array}{l}\text { Handles local maximum issue } \\
\text { and high reliability in data } \\
\text { delivery }\end{array}$ \\
\hline TBHGR [143] & $\begin{array}{l}\text { Handling local maximum and } \\
\text { providing routing efficiency in } \\
\text { heterogeneous networks }\end{array}$ & Random Waypoint & $\begin{array}{l}\text { Heterogeneous node mobility } \\
\text { based geographic routing }\end{array}$ \\
\hline RoRo-LT[144] & $\begin{array}{l}\text { Spatiotemporal history-based } \\
\text { location observation }\end{array}$ & $\begin{array}{l}\text { Map-based } \\
\text { movement }\end{array}$ & Replication avoidance \\
\hline GeoSpray [145] & $\begin{array}{l}\text { High routing efficiency and } \\
\text { effective resource utilization }\end{array}$ & Map-based model & $\begin{array}{l}\text { Duplication avoidance in } \\
\text { packet delivery }\end{array}$ \\
\hline $\mathrm{AaR}[146]$ & Reduce message replication & $\begin{array}{l}\text { Map-based } \\
\text { movement }\end{array}$ & $\begin{array}{l}\text { Solves the local maximum } \\
\text { issue }\end{array}$ \\
\hline TDOR [147] & $\begin{array}{l}\text { Trajectory based opportunistic } \\
\text { data forwarding }\end{array}$ & Map-based & $\begin{array}{l}\text { Minimize redundant routing } \\
\text { overhead }\end{array}$ \\
\hline $\mathrm{CaD}[148]$ & Efficient routing decision & Map-based & $\begin{array}{l}\text { Handling the local maximum } \\
\text { issue }\end{array}$ \\
\hline DAER [149] & $\begin{array}{l}\text { It aims to prevent redundant data } \\
\text { transmission }\end{array}$ & $\begin{array}{l}\text { Trace based realistic } \\
\text { model }\end{array}$ & $\begin{array}{l}\text { Reduce delay in data delivery } \\
\text { over sparse networks }\end{array}$ \\
\hline POR [150] & $\begin{array}{l}\text { Reduce data replication by } \\
\text { selecting long distance path }\end{array}$ & Real traces & $\begin{array}{ll}\text { Minimized } & \text { redundant } \\
\text { transmission } & \\
\end{array}$ \\
\hline geoDTN [151] & $\begin{array}{l}\text { Effectively handles the local } \\
\text { maximum issue }\end{array}$ & $\begin{array}{l}\text { Trace and real-time } \\
\text { based }\end{array}$ & $\begin{array}{l}\text { High data delivery in sparse } \\
\text { networks }\end{array}$ \\
\hline GeoDTN+Nav [152] & $\begin{array}{l}\text { Selecting best delay-tolerant } \\
\text { forwarders }\end{array}$ & $\begin{array}{l}\text { Realistic urban } \\
\text { mobility }\end{array}$ & Enhanced packet delivery \\
\hline
\end{tabular}

Table 15 Mobility Models Applied to Geographical Routing in DTNs

The geographical DTN routing protocols generally utilize three mobility models: random, map-based, and trace-based realistic for protocol performance analysis. The Vector Routing [139], Delegation Geographic Routing (DGR) [140], History-Based Vector Routing (HVR) [141], GeographicBased Spray-and-Relay (GSaR) [142], and The-Best Geographic-Relay (TBGR) and TBHGR [143] geographic DTN routing protocols are falling under random mobility model category. Further, the RoRo-LT [144], GeoSpray provide results nearly closer to realistic environments. The DTN social mobility models track the human mobility patterns in a real-time environment. Tracking human mobility and adopting such mobility patterns in mobility model design is a challenging task. Table 15 discusses the various mobility models applied to geographical DTN routing. 


\section{SURVEY ARTICLE}

\section{THE IMPACT OF MOBILITY ON LOCATION UPDATE SCHEMES IN GEOGRAPHICAL ROUTING TECHNIQUES IN MWNS}

The essential factor in geographic routing is the utilization of node position information. Though geographic routing is attractive, it is necessary to maintain the list of one-hop neighboring nodes accurately. Thus, every router needs to update its position to the one-hop neighbors. To reduce the location uncertainty, each mobile node has to report its original location from time to time. However, if the frequency of node mobility is low, the nodes waste their resources by processing the location update service frequently. On the other hand, if the nodes do not perform the location update frequently, inaccurate location information may be used by them for packet routing results in a waste of network bandwidth and routing failure. Thus, a scalable location service is essential for geographical routing [153]. The location update schemes differ depending on the mobility model supported by the network. This section discusses the location update schemes supported by various MWNs such as MANET, WSN, VANET, UWSN, FANET, and DTN.

\subsection{Location Services}

The central problem of location update service is to devise algorithms that minimize routing overhead and improve location information accuracy. Every node in the network is responsible for maintaining its location information to reduce the routing cost or overhead by considering the advantage of the mobility pattern. Location service is accountable for providing the location of a destination node to route the data packets efficiently. A node obtains the location information from the location service when it demands data communication. This service not only gets the location of the destination, but it also needs to update its neighbor list information for packet routing to the identified destination. However, the design of location services and location update schemes suitable for all mobile environments is challenging. As the frequent location update to the servers and neighboring nodes lead to high routing overhead, the rate of network scalability and node mobility linearly degrades the efficiency of geographic routing protocol. The performance of the mobility model on scalable location services is evaluated in [154].

Types of Location Services: The geographic routing protocols employ location servers for the sources to obtain the location of the destination. Each node updates its location information to the location servers using a handful of messages to achieve this. Several location services have been used for geographical routing to obtain location information. The negative impact of node mobility is high on the location server while maintaining an accurate neighbor list at each node in the network. Generally, the location services for MWNs have been categorized into two types: infrastructure- less and infrastructure-based services. In both types, the flooding and mapping-based location services are utilized for location updating.

Flooding Based Location Service: The flooding-based location update method is classified into proactive and reactive approaches. The proactive location services proactively compute the location of nodes that are in the network. In that, every node broadcasts its location information to others periodically.

Mapping Based Location Service: The mapping-based location update is divided into quorum and hashing-based location services. The quorum-based location service replicates the location information in multiple location servers. A node that needs to forward the data packet to the particular destination transmits the query packets to the distributed location servers for identifying the position information of the destination. The mobile nodes or the location servers are dispersed in the network to improve the routing performance.

\subsection{Location Update Schemes}

Even the source node obtains the destination location of the infrastructure-based or infrastructure-less location servers, and each node maintains the local topology information for routing the data packets towards the destination to reduce the location overhead. To reduce the local topology information uncertainty, each node in the network needs to update its neighbor list periodically. The location update services start with the hello or beacon packets to neighboring nodes in the communication range. The location services are classified into static and dynamic location update scheme based on the environment. In the static location update schemes, each node sends the information update messages to others in the communication range. However, in a dynamic location update scheme, the node mobility factors such as distance, speed, and time are considered. The performance of location update schemes depends only on the mobility model used in the simulation but is not based on the network characteristics. Thus, this section lists the commonly used location update schemes in Table 16.

Distance-Based Beaconing: Each node predicts the distance; it moves and updates the location information in their neighboring nodes when the original distance moved exceeds the threshold range. In other words, a node sends the information update packets when it is moved more than the specified distance level to avoid outdated location information. The node removes the location information of another node when it does not receive the information update packets from the neighboring node while it moves more than the specified distance. Mostly the distance threshold determination mechanism employs linear, symmetric, and iterative approaches. 


\section{SURVEY ARTICLE}

In a predictive distance-based information update scheme, each node sends the beacon packets, including location and mobile speed. The prediction schemes use the probability density function to predict the location of a neighboring node after its mobility. However, the capture of the correlation of the node velocity is varied under different scenarios.

Speed Based Beaconing: The dynamic nature of network topology and node speed affects the node's prediction capability, which leads to packet routing failure. With constant node mobility, node mobility prediction is easy, but it is difficult under an environment where the mobile nodes have different speeds. The node speed-based beacon broadcasting has commonly named speed-based beaconing. In that, the beacon interval range is predefined based on the node velocity. The expired location information is identified by applying the beacon time-out interval. Piggybacking is utilized to transfer the time-out interval values through information update packets. The time-out interval is compared with its own when it receives the beacon packet, and it selects the short time-out interval value for providing precise location information. Thus, a low-speed node selects the short beacon time-out interval for the fast-moving neighbors, and hence, it can solve the first problem presented in the distance-based beaconing. However, a fast-moving node may not detect the slow nodes under a widely varying network topology in speed-based beaconing.

\begin{tabular}{|c|c|c|c|c|}
\hline $\begin{array}{c}\text { Location } \\
\text { Update Scheme }\end{array}$ & $\begin{array}{c}\text { Optimization } \\
\text { Metrics }\end{array}$ & $\begin{array}{c}\text { Update } \\
\text { Mechanism }\end{array}$ & Merits & Demerits \\
\hline $\begin{array}{l}\text { Continuous } \\
\text { Beaconing }\end{array}$ & No & Flooding & $\begin{array}{ll}\text { Accurate } & \text { Location } \\
\text { information } & \end{array}$ & High routing overhead \\
\hline \multirow{4}{*}{$\begin{array}{l}\text { Dynamic } \\
\text { Beaconing }\end{array}$} & Distance & $\begin{array}{l}\text { Distance } \\
\text { Threshold }\end{array}$ & $\begin{array}{l}\text { Only high mobile nodes } \\
\text { broadcast beacons frequently }\end{array}$ & $\begin{array}{l}\text { High routing overhead in } \\
\text { group mobility model }\end{array}$ \\
\hline & Time & Fixed Interval & $\begin{array}{l}\text { Support individual mobility } \\
\text { model with constant time }\end{array}$ & $\begin{array}{l}\text { Not support delay-sensitive } \\
\text { applications }\end{array}$ \\
\hline & Speed & $\begin{array}{l}\text { Distance } \\
\text { Threshold }\end{array}$ & $\begin{array}{l}\text { Support randomly moving } \\
\text { nodes }\end{array}$ & $\begin{array}{ll}\text { Reduces } & \text { network } \\
\text { connectivity } & \end{array}$ \\
\hline & State & $\begin{array}{l}\text { Transmission } \\
\text { state }\end{array}$ & $\begin{array}{l}\text { In high traffic network, } \\
\text { routing overhead is reduced }\end{array}$ & $\begin{array}{l}\text { Cannot predict the local } \\
\text { maximum problem }\end{array}$ \\
\hline
\end{tabular}

Table 16 Location Update Schemes in Geographical Routing

Reactive Beaconing: The source node floods the information update packets to its nearby nodes on demand in reactive beaconing. Each node ensures the neighbor list accuracy before initiating the data forwarding. A node in the communication range can overhear the request packet sent from one node to another and updates its neighboring nodes [155]. The beaconing is commenced when the beaconing interval exceeds the time difference between the current and last beaconing receiving time. Thus, it reduces the routing overhead significantly. The beaconing commences when a node moves beyond a particular area, and the data packets are delivered promptly. However, high routing overhead and failure to predict the local maximum due to the beaconing limitation to one-hop neighbors are significant challenges in reactive beaconing.

Time-Based Beaconing: In this scheme, each node updates the neighbor list information periodically [156]. The determination of the beaconing interval is challenging to design under dynamic network topology. For implementation, existing works set the timer for the beaconing interval at each node by hardware or software. The mobile node does not need to update the location information during the time between update intervals. It reduces the routing overhead than other beaconing schemes. Instead of using a constant beaconing interval, this approach varies the interval time based on mobility and traffic load rate. The main drawback of timebased beaconing is generating unwanted beacons for each time interval, even under a low mobility network. This mechanism is not appropriate for delay-sensitive applications. Thus, the linear model based time determination performs better than the constant time-based location update under various scenarios.

\subsection{Mobility Adaptive Location Update Schemes}

Based on different mobility patterns, [157] conducts a simulation to demonstrate the impact of location error on GPSR performance in the MANET environment. Adaptive position update schemes can significantly improve routing performance [158]. The main issues resulting from the unpredictable node mobility are loop formation and link loss, and the impact of various mobility patterns is different for multiple scenarios. Inflexible beaconing for various mobility models increased the stale information in the local topology cache, and some of the routing protocols have been proposed to mitigate the beaconing effect on location inaccuracy. The 


\section{SURVEY ARTICLE}

Neighbor Position Verification (NPV) [159] enables the fully distributed location service without trusted nodes in the network. Every node quickly verifies the node position information using local observations, but they do not make any lengthy interaction. However, the beacon broadcasting strategy becomes less efficient under a highly dynamic network topology.

\subsubsection{Need for Mobility Adaptive Location Update Schemes}

Every beacon packet includes the position update information and their speed in the network. However, there is no solution to control the routing overhead and traffic rate. The beacon packet generation significantly increases with the node mobility rate, and it stimulates a high routing overhead and communication cost in the network. The mobility adaptive location update scheme alters the beacon broadcast interval based on the dynamics of node mobility. Also, the external location service needs to identify the position information of mobile nodes that consumes high power. A high-frequency beaconing strategy such as APU maintains the accurate local map for its neighboring nodes to alleviate node mobility impact on routing. For example, Predictive location-based schemes improve the QoS [160], and the Adaptive Position Update (APU) scheme [158] employs on-demand learning and mobility prediction effectively.

\subsubsection{Mobility Prediction Schemes}

A new approach to track the node mobility in the network is mobility prediction. The main feature of the APU is the mobility prediction that follows the node movement when it is not receiving the beacon update packets until the beaconing interval is timed out. Thus, the node mobility prediction supports maintaining the right nodes' topology information. The APU scheme in [158] uses linear kinetic equations for determining the beacon interval and beaconing timeout interval. Also, it considers other routing metrics that are obtained during the last beaconing. The mobile node finds the original location information after its movement and compares it with the predicted value. Then, it sends the location update packets to its neighboring nodes when the actual location profoundly deviates from the expected value.

The mobile nodes do not broadcast the beacon packets until the deviation exceeds the measured Acceptable Error Range (AER). The determination of AER considers the routing metrics such as node communication range and node energy. Thus, the location deviation within the AER range is tolerable, even with the high-frequency mobile nodes. The node ensures the accuracy of the neighbor list when overhearing the data transmission. The user mobility models are classified, and state that mobility attributes to predict node mobility in the network is complex under frequently changing network topology. According to the last beaconing information, such as the node's location and velocity, the
Gauss-Markov model updates the local topology cache. There are three methods to predict node mobility in a MANET environment: physical topology, movement history, and logical topology-based mobility prediction.

Movement History-Based Mobility Prediction: This approach maintains the history of node mobility information and predicts the location of a node in the future [161]. It is employed to pre-allocate the network resources, packet routing and assigns the data routing at the predicted new location. However, in the case of unpredictable or inaccurate predictions, the history-based mobility prediction is not appropriate. The movement history-based approaches use different mobility metrics such as movement circle, movement tracking, and Markov chain mobility model for modeling the behavior of node mobility. The regularity of human movement over a period is measured from the movement history. However, it is challenging to support highquality MANET applications using movement history-based mobility prediction mechanism, for instance, mobile applications such as military, disaster areas, and emergency searching applications.

Physical Topology Based Mobility Prediction: This algorithm uses MANET and GPS receiver characteristics, which are used to obtain the original location information and node's mobility information [162]. A node may not wholly follow the random mobility model in real-time, but the node mobility can be predictable. The link expiration time and link availability time are the main metrics to predict the network topology state in the future. It reconstructs the communication route before the link disconnection without incurring a high routing overhead. In a MANET, the wireless link between two nodes in the communication range is formed. The mobility prediction is based on the link expiration time of the wireless link established between mobile nodes. The expiration time of a routing path is determined using the measured link expiration time. A new route is configured before the estimated link is disconnected. However, the main drawback of the link estimation-based mobility prediction is that it needs accurate mobility and location information. Another metric utilized to predict the future status of wireless links is probabilistic link availability. The link availability refers to the activation time of a wireless connection between two mobile nodes within the communication range of each node. These schemes achieve better routing performance under less volatile environments, leading to high routing overhead under highly volatile environments.

Group Mobility and Network Partition Prediction: Mobile nodes follow different mobility models in the group mobility model. It divides the network into several sub-networks. The network partition time is predicted to enhance the efficiency of the routing protocol and avoids the problems incurred by the network partition. The randomly located nodes are 


\section{SURVEY ARTICLE}

grouped for group motion, and a group leader allows each node randomly located in the region of the reference point to move in the network in a controlled manner. In a network, the mobile nodes contain several mobility models, and in which the mobile nodes are dispersed and intermixed. The separated time of the sub network can be estimated for any node under any mobility model.

Cluster-Based Mobility Prediction: Each node belongs to the cluster, and this approach defines the node's position for the cluster head it belongs to [163]. To attain accurate mobility prediction, it restricts the high probability cluster change areas. Moreover, it divides the cluster into three areas: high cluster change, low cluster change, and no cluster change. In no cluster change region includes nodes located in the communication range. The nodes in the no-changed cluster do not satisfy the conditions for obtaining membership in other neighbor clusters. The low cluster change region contains the reachable nodes by all the nodes in each cluster.
The change probability of these clusters is very low. The high cluster change area includes the nodes that are unreachable by any node in the network.

Evidence-Based Mobility Prediction: In [164], contextual information is utilized as evidence for predicting the node mobility in the network. This mobility prediction approach and traveling trajectory use mobility profile, preferences, and spatial information. There is a need for adaptive routing to the demands of applications. Moreover, it does not need to maintain the history of node movements. Furthermore, the DS theory of evidence-based mobility prediction scheme describes the node's uncertainty level due to its unpredictable node mobility. Thus, the evidence-based mobility prediction achieves high routing performance even under a highly dynamic network topology. Table 17 compares different mobility adaptive location update methods for geographical routing in MWNs.

\begin{tabular}{|c|c|c|c|c|}
\hline $\begin{array}{l}\text { Geographic Routing } \\
\text { Protocol }\end{array}$ & $\begin{array}{l}\text { Type of } \\
\text { Network }\end{array}$ & Routing Type & Mobility Model & Location Update Type \\
\hline EM-GPSR [38] & & & Random waypoint & Time-based beaconing \\
\hline $\begin{array}{l}\text { Contention-based routing } \\
\text { [39] }\end{array}$ & & Greedy & Random waypoint & $\begin{array}{l}\text { Time-based periodic } \\
\text { beaconing }\end{array}$ \\
\hline PS-ROGR [40] & & & Random waypoint & $\begin{array}{l}\text { Mobility adaptive trajectory- } \\
\text { based }\end{array}$ \\
\hline QGeo [42] & & Face & $\begin{array}{l}\text { Gaussian Markov } \\
\text { random mobility }\end{array}$ & $\begin{array}{l}\text { Time-based periodic } \\
\text { beaconing }\end{array}$ \\
\hline GOAFR+ [43] & & Greedy-Face- & Random Model & $\begin{array}{l}\text { Distributed GPS assisted } \\
\text { location update }\end{array}$ \\
\hline TAG [44] & & $\begin{array}{l}\text { Greedy } \\
\text { Routing }\end{array}$ & Random waypoint & $\begin{array}{l}\text { Local topology-based } \\
\text { location update }\end{array}$ \\
\hline FQ-AGO [45] & MANET & & $\begin{array}{l}\text { Modified random } \\
\text { waypoint }\end{array}$ & $\begin{array}{l}\text { Region-based and Mobile } \\
\text { Group based location update }\end{array}$ \\
\hline 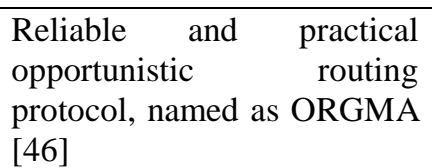 & & Opportunistic & Random Way Point & Periodic flooding based \\
\hline CORMAN [48] & & & Random Waypoint & Mobility based updation \\
\hline GPMOR [56] & $\begin{array}{l}\text { Aircraft } \\
\text { UAV }\end{array}$ & \multirow{5}{*}{ Greedy } & Gauss-Markov & $\begin{array}{l}\text { Time-based periodic } \\
\text { beaconing }\end{array}$ \\
\hline MPGR [57] & $\begin{array}{l}\text { Aircraft } \\
\text { UAV }\end{array}$ & & Gauss-Markov & $\begin{array}{l}\text { Time-based periodic } \\
\text { beaconing }\end{array}$ \\
\hline GLSR [51] & $\begin{array}{l}\text { Aircraft } \\
\text { UAV }\end{array}$ & & Random model & Local topology-based update \\
\hline GRAA [52] & $\begin{array}{l}\text { Quadcopter } \\
\text { drone UAV }\end{array}$ & & Random Walk & Periodic beaconing \\
\hline $\begin{array}{l}\text { Greedy forwarding } \\
\text { geographical routing on the } \\
\text { Internet of Drones [55] }\end{array}$ & $\begin{array}{l}\text { Drones } \\
\text { UAV }\end{array}$ & & Random model & Continuous beaconing \\
\hline
\end{tabular}


International Journal of Computer Networks and Applications (IJCNA)

DOI: 10.22247/ijcna/2021/209993 Volume 8, Issue 5, September - October (2021)

\section{SURVEY ARTICLE}

\begin{tabular}{|c|c|c|c|c|}
\hline AeroRP [59] & $\begin{array}{l}\text { Test } \\
\text { Aircrafts } \\
\text { UAV }\end{array}$ & \multirow{3}{*}{ Greedy } & Random Waypoint & Proactive updates \\
\hline LADTR [61] & $\begin{array}{l}\text { Drone and } \\
\text { Ferry UAVs }\end{array}$ & & Gauss-Markov & $\begin{array}{l}\text { Periodic beacons of UAV } \\
\text { status }\end{array}$ \\
\hline CORF [65] & $\begin{array}{l}\text { Drones } \\
\text { UAV }\end{array}$ & & $\begin{array}{l}\text { Shortest Path Map- } \\
\text { Based Movement }\end{array}$ & Map-based location update \\
\hline CRUV [64] & $\begin{array}{l}\text { Drones } \\
\text { UAV }\end{array}$ & $\begin{array}{l}\text { Greedy and } \\
\text { opportunistic }\end{array}$ & Random walk & Periodic beaconing \\
\hline GRCS [84] & \multirow[b]{2}{*}{ WSN } & \multirow[t]{2}{*}{ Greedy } & Random Waypoint & $\begin{array}{l}\text { Cluster-based continuous } \\
\text { beaconing }\end{array}$ \\
\hline Elastic Routing [85] & & & Random Mobility & Frequent location update \\
\hline REBAR [94] & \multirow{7}{*}{ UWSN } & \multirow[b]{2}{*}{ Greedy } & $\begin{array}{l}\text { Random } \\
\text { movement }\end{array}$ & Periodic beaconing \\
\hline VBF [92] & & & Random walk & Distance-based beaconing \\
\hline SBR-DLP [98] & & Face Routing & $\begin{array}{l}\text { Pre-planned } \\
\text { movement }\end{array}$ & $\begin{array}{l}\text { Pre-planned path based } \\
\text { location prediction }\end{array}$ \\
\hline SORP [100] & & \multirow{3}{*}{ Opportunistic } & $\begin{array}{l}\text { Meandering } \\
\text { Current Mobility } \\
(\mathrm{MCM})\end{array}$ & Depth based location update \\
\hline VAPR [101] & & & $\begin{array}{l}\text { Meandering } \\
\text { Current Mobility }\end{array}$ & Flooding based beaconing \\
\hline DCR [99] & & & Vertical movement & $\begin{array}{l}\text { Sonobuoys distance-based } \\
\text { beaconing }\end{array}$ \\
\hline GEDAR [102] & & $\begin{array}{l}\text { Greedy } \\
\text { opportunistic }\end{array}$ & $\begin{array}{l}\text { Meandering } \\
\text { Current Mobility } \\
(\mathrm{MCM})\end{array}$ & Distributed location update \\
\hline CAR [113] & \multirow{8}{*}{ VANET } & \multirow{3}{*}{ Greedy } & $\begin{array}{l}\text { Car mobility } \\
\text { model }\end{array}$ & $\begin{array}{l}\text { Pre-loaded digital map } \\
\text { based beaconing }\end{array}$ \\
\hline GRANT [114] & & & $\begin{array}{l}\text { Car mobility } \\
\text { model }\end{array}$ & Map-based beaconing \\
\hline PBR-DV [115] & & & Trace based & Flooding based beaconing \\
\hline VADD [163] & & \multirow{4}{*}{ Opportunistic } & $\begin{array}{l}\text { Stochastic mobility } \\
\text { model }\end{array}$ & Digital map based update \\
\hline LDAOR [121] & & & $\begin{array}{l}\text { Map-based } \\
\text { movements }\end{array}$ & $\begin{array}{l}\text { Map and delivery } \\
\text { probability-based update }\end{array}$ \\
\hline PRO [123] & & & Realistic & Distributed beaconing \\
\hline 3-Parameter Routing [124] & & & $\begin{array}{l}\text { Real vehicle } \\
\text { movement patterns }\end{array}$ & GPS-assisted beaconing \\
\hline $\begin{array}{l}\text { Hybrid opportunistic routing } \\
\text { protocol [119] }\end{array}$ & & $\begin{array}{l}\text { Greedy and } \\
\text { opportunistic }\end{array}$ & Random direction & Periodic beaconing \\
\hline RoRo-LT [144] & $\begin{array}{l}\text { Pocket } \\
\text { Switched } \\
\text { Networks } \\
\text { DTN }\end{array}$ & \multirow[b]{2}{*}{ Opportunistic } & $\begin{array}{l}\text { Map-based } \\
\text { movement }\end{array}$ & $\begin{array}{l}\text { Mobile trajectory history- } \\
\text { based location update }\end{array}$ \\
\hline TDOR [147] & VCPS DTN & & Map-based & Map trajectory-based \\
\hline
\end{tabular}

Table 17 Mobility Adaptive Location Update Methods for Geographical Routing in MWNs 


\section{SURVEY ARTICLE}

\section{FUTURE WORK}

Realistic mobility models are crucial for improving the efficiency of geographical routing. The commonly used alternative method is to simulate the geographical routing over realistic movement patterns. Hence, the accuracy of performance evaluation of geographical routing mostly depends on the mobility patterns and their reflection on reality. Mobility poses significant challenges to the routing layer, and it impacts numerous network characteristics, such as network connectivity, capacity, and coverage in wireless networks. Human mobility modeling and prediction can significantly assist geographical routing in emerging MWN applications.

\subsection{Future Directions}

Recently, wireless network applications have emerged in several areas ranging from safety to comfort applications. Thus, it increases the exploration and research on wireless communication in two aspects: routing and mobility. Node movement plays a vital role in the wireless communication research field with the complexities of scenario characteristics. Future research in this scenario needs to realize the critical aspect of attaining network-specific goals in mobility model features. An increase in mobility intensity forces the nodes to cover a large surface area and induces more contact opportunities between nodes. However, it limits the opportunities for establishing and maintaining a wireless connection between nodes. Integrating the realistic mobility model characteristics in geographical routing decisions improves efficiency.

The recent evolution of wireless communication turns to focus on modeling as well as predicting mobility. The application of human mobility prediction became prominent in wireless networks [165]. Previously, a popular method for modeling mobility was the random waypoint, which generates random movement patterns. However, the realistic movement patterns are not random in the applications of wireless networks. Instead, the mobility of humans or wireless devices may be predictable to some extent. The efficiency of geographical routing in wireless networks is significantly improved when the movement models or the contact probability between mobile devices are predicted in advance. The mobility models have recently reached several developments, so the recent trends in modeling mobility have led to many changes in developing geographical routing over wireless networks.

Recently, mobility research has shown a growing interest in trace-based mobility model development [166]. To simulate the real movement of wireless nodes, it is suitable to use datasets from realistic scenarios for modeling mobility, mimicking human mobility patterns. The trace-based mobility model collects traces and analyzes them to find specific patterns. The traces are collected from the actual measurements. It is used to predict the node mobility to some extent and contact information between a pair of nodes. Thus, the implementation of a trace-based mobility model tends to better forward decisions. The latest research on trace-based mobility models is categorized into three types: modeling mobility dynamics theoretically, quantifying uncertainty in mobility prediction, and leveraging stochastic optimization algorithms. The third category becomes popular, based on Markov model variants, machine learning techniques, and neural network architectures. Most of the works use extensions of Markov models regardless of the unclear association with the human mobility dynamics [167]. Moreover, the probabilistic models suffer from data sparsity problems and lack fine granularity in prediction. The data mining methods generate association rules and periodic patterns for mobility prediction with or without spatiotemporal distance. Next, deep learning networks, such as Recurrent Neural Network (RNN), are used to predict node mobility [168].

\subsection{Changing Trends in Geographical Routing with Latest Mobility Models}

The geographical routing forwards packets in a one-hop manner. The selection of relay nodes from the neighbor list is based on anyone or multiple link metrics. It is prominent to consider the knowledge of contact information of nodes due to the frequent node mobility. For example, in link quality metrics-based data forwarding, the stable packet forwarding is realized for a selected neighbor until the packet eventually reaches the node. A packet is relayed more intelligently when the node mobility is predicted accurately. The mobile nodes with long inter-contact times may never meet at all. The geographical routing schemes can utilize the node mobility knowledge and perform well by estimating the future contact probabilities in advance for a pair of mobile nodes. The tracebased mobility model using a real-time dataset provides an opportunity to estimate future contact probability between mobile nodes - the Markov model usage in modeling mobility despite the unclear association with the human mobility dynamics. Thus, recent research works mostly use machine and deep learning models for mobility modeling. Using machine learning and artificial intelligence, location and mobility prediction can significantly improve routing performance in a highly dynamic, pervasive MWN environment.

The suitability of trace-based mobility models for wireless networks can be decided based on the following factors. The suitability of trace-based mobility models relies on the analysis method selected. The data mining techniques are efficient for analyzing the future contact details between nodes. It requires more datasets to explore the real mobility scenarios. To avoid biased results, the duration of available 


\section{SURVEY ARTICLE}

datasets has to be extended. Several traces need to be generated from the dataset.

\subsection{Impact of Recent Mobility Models on Geographical Routing over MANET, VANET, and FANET}

The previous research validates that the mobility patterns in a MANET environment are not entirely random. Instead, the random mobility, the devices that humans carry are predictable. In conventional, several works attempt to model human mobility. Even though the solutions are developed for understanding the movement patterns, it is essential to change the trends in the human mobility model by considering the obstacles, especially in geographical constraints, while crossing the obstacles. It also leads the routing protocol to several changes in MANET. Designing good mobility models by integrating smooth characteristics of FANETs is fundamental for ad hoc mobility models to reflect realistic flight behavior. Also, it is necessary to provide an in-depth analysis of UAV movement patterns in a real-time environment. Another future work is to adaptive localization mechanisms for improving geographic routing efficiency.

Modeling the mobility of devices in MANET has to define precise characteristics of the movement of devices. The highly dynamic network topology in the MANET and the nature of UAV aerodynamic mechanism and mechanical flight in FANET are significantly challenging to model their motion behavior in simulation. The trace-based mobility models based on realistic datasets are suitable for MANETs. The applications of infrastructure-less networks are mostly limited in area and communication range. However, there is no significant impact if the mobility model does not capture the node movement at the microscopic level. Thus, the realistic dataset-based trace creation is suitable for MANET. However, several factors decide the motion behavior of VANET and UAVs, such as the path, speed, and atmospheric or road condition.

Trace-based mobility does not consider some of the key issues that create notable impact. The first aspect is the curve of the road. The realistic vehicles in VANET and FANET changing their speed by applying acceleration and deceleration. For instance, even minor variations in its movement due to turbulence or speed differences impact communication and safety. These characteristics or behaviors are not observed and modeled in several mobility models, and most of them infinitely accelerate the vehicles, which change the speed significantly. In VANET and FANET, it is essential to consider the safety requirements, as the safety distance, to avoid collisions. Thus, the data mining techniques are suitable for the geographical routing protocols over VANET and FANET applications when they create and analyze traces using multiple realistic data sets with long duration. The importance of vehicle movement in reflecting and inducing a realistic road environment in simulation necessitates the design and application of realistic mobility models in the core of geographical routing. Some conventional mobility models rely on micro-mobility aspects such as vehicle speed, direction, and geographical constraint on a road, and other models focus on the sociological aspects. It is imperative to jointly focus on micro and macro mobility factors to support a more realistic mobility model and adapt the simulation environment. Integrating IoT with VANET creates flexible future enhancement in ITS and also offers real-time responses to the drivers.

\subsection{Impact of Recent Mobility Models on Geographical Routing over WSN, UWSN, IoT, and DTN}

Modeling macro mobility in WSN is a significant challenge to cope with the constraints in the sensor network, such as low battery power capabilities. Energy-efficient data collection and mobility management in WSN demand great efforts in the analysis of mobile sinks. The mobility model has to reflect various scenarios depending on the applications, such as hole due to dead nodes and damage of sensors. The mobility model for sensor networks deployed on animals that move very slowly and sometimes stay for a long time at the same location; the speed of the motion element must accommodate the differences. However, in running cases, speed increases.

The recent mobility models are not always adequate for the networks, such as WSN, UWSN, IoT, and DTN, for the following reasons. It is difficult to adequately capture and analyze the frequently generated data from sensor networks, such as WSN, UWSN, and IoT. The DTN is a shared network for interconnecting heterogeneous gateways or proxies. It makes difficulties to generate multiple data set for long duration. Suppose the trace-based mobility models exploit only a limited number of traces. It does not capture all the scenarios, and the extracted mobility patterns based on a few traces are not precise. Improper analysis of the spatial and temporal structure of mobility models with small-size datasets tends to unrealistic mobility patterns in sensor networks. It shows a significant deviation from realistic applications. Thus, trace-based mobility models' suitability to geographical routing in various wireless networks is based on the collected datasets, size, and selected techniques for data analysis.

IoT has played a vital role in several MWN applications such as health care automation, industrial monitoring, smart city, smart transportation, and agriculture in recent years. Generally, the IoT sensor nodes collect the data about the monitoring environment and forward the data to external internet services. Thus, the IoT enhances the value of realtime services or improves the efficiency of real-time applications. Location management is a significant burden on IoT due to the resource constraints that need support from edge devices. In the future, make a formal plan to make this study provide a direction to the Internet of Things (IoT) domain and include suitable mobility models and geographic 


\section{SURVEY ARTICLE}

routing protocols for IoT networks, as it is a keystone in MWNs. Recently, geographical routing protocols have been proposed for IoT applications [169][170] that radically provide new directions in using geographical routing in IoT.

\section{CONCLUSION}

Multi-hop wireless networks (MWNs) form a foundation for many modern wireless networks in real-time environments and have increased the necessity of mobility models and geographical routing. Geographical routing is a prominent routing solution to a wide range of MWNs. Realistic mobility models are vital for evaluating the protocols in simulation environments. Mobility models significantly impact various forms of recent MWNs and their geographical routing solutions. To demonstrate the impact of mobility models on various MWNs, this work surveys mobility models and their impact on various geographic routing protocols. Besides the mobility models and their impacts, location management issues and location prediction techniques are discussed. Although several works have been proposed for routing service over various mobility models, there is significant scope for future research in geographical routing and mobility models developed recently. Finally, this survey concludes with future directions.

\section{REFERENCES}

[1] Macro Conti, Silvia Giordano, "Multi-hop Ad-hoc networking: The Reality", IEEE Communications Magazine, Vol. 45, No.4, pp. 88-95, 2007

[2] Ruhrup, Stephan, "Theory and practice of Geographic routing", Ad Hoc and Sensor Wireless Networks: Architectures, Algorithms and Protocols, pp. 1-37, 2009

[3] Chlamtac Imrich, Marco Conti, and Jennifer J-N. Liu, "Mobile ad hoc networking: imperatives and challenges", Ad hoc networks, Vol.1, No.1, pp 13-64, 2003.

[4] Bekmezci, Ilker, Ozgur Koray Sahingoz, and Şamil Temel, "Flying ad-hoc networks (FANETs): A survey”, Ad Hoc Networks, Vol.11, No. 3, pp.1254-1270, 2013.

[5] Priyanka Rawat, Kamal Deep Singh, Hakima Chaouchi, Jean Marie Bonnin, "Wireless sensor networks: a survey on recent developments and potential synergies", The Journal of Super computing, Vol. 68, No. 1, pp 1-48, 2014.

[6] Tong Wang, Yue Cao, Yougzhe Zhou, Pengcheng Li, "A Survey on Geographic Routing Protocols in Delay/Disruption Tolerant Networks", International Journal of Distributed Sensor Networks, 2016, http://dx.doi.org/10.1155/2016/3174670

[7] Souaad Boussoufa-Lahlaha, FouziSemchedinea, LouizaBoualloucheMedjkounea, "Geographic routing protocols for Vehicular Ad hoc NETworks (VANETs): A survey", Vehicular Communications, Vol. 11, pp. 20-31, 2018.

[8] Tasneem Darwish, Kamalrulnizam Abu Bakar, Ahlam Hashim, "Green geographical routing in vehicular ad hoc networks: Advances and challenges", Computers \& Electrical Engineering, Vol.64, pp. 436-449, 2017.

[9] Cadger Fraser, Kevin Curran, Jose Santos, and Sandra Moffett, "A survey of geographical routing in wireless ad-hoc networks", IEEE Communications Surveys \& Tutorials, Vol. 15, No. 2, pp. 621-653, 2013

[10] Nakano, Keisuke, Masakazu Sengoku, and Shoji Shinoda, "Effect of mobility on connectivity of mobile multihop wireless networks",
IEEE $55^{\text {th }}$ Conference on Vehicular Technology, Vol. 3, pp. 11951199, 2002.

[11] Son, D., Helmy, A. and Krishnamachari, B, "The effect of mobilityinduced location errors on geographic routing in ad hoc networks: analysis and improvement using mobility prediction", In IEEE Wireless Communications and Networking Conference, Vol.1, pp.189-194, Atlanta, GA, USA, 2004.

[12] T. Camp, J. Bowling, and V. Davies, "A survey of mobility models for ad hoc network research", Wireless Communication and Mobile Computing, Vol.2, No. 5, pp.483-502, 2002.

[13] Pan, Jianli, and Raj Jain, "A survey of network simulation tools: Current status and future developments", Vol.7, No. 6, pp. 1-13, 2008.

[14] Treurniet, J, "A taxonomy and survey of microscopic mobility models from the mobile networking domain", ACM Computing Surveys (CSUR), Vol.47, No.1, pp. 1-32, 2014

[15] Gorawski Michal, and Krzysztof Grochla, "Review of mobility for performance evaluation of wireless networks", Advances in Intelligent Systems and Computing, Springer, Vol. 242, pp. 567-577, 2014.

[16] Vaity, N. P., \& Thombre, D. V, "A survey on vehicular mobility modeling: flow modeling", International Journal of Communication Network Security, Vol.1, No.4, 21, 2012

[17] Batabyal, Suvadip, and Parama Bhaumik, "Mobility models, traces and impact of mobility on opportunistic routing algorithms: A survey”, IEEE Communications Surveys \& Tutorials, Vol.17, No. 3, pp. 1679-1707, 2015.

[18] B. Karp and H. T. Kung, "GPSR: Greedy Perimeter Stateless Routing for Wireless Networks", in Proceedings of ACM Mobicom, pp. 243-254, Boston, Massachusetts, USA, 2000.

[19] E. Kranakis, S. O. C. Science, H. Singh, and J. Urrutia, "Compass Routing on Geometric Networks," in Proc. 11 th Canadian Conference on Computational Geometry, pp. 51-54, Ottawa, Canada, 1999.

[20] F. Kuhn, R. Wattenhofer, and A. Zollinger, "An algorithmic approach to geographic routing in ad hoc and sensor networks", IEEE/ACM Transactions On Networking, Vol. 16, No. 1, pp. 51-62, 2008.

[21] J. Na and C. Kim, "GLR: A novel geographic routing scheme for large wireless ad hoc networks," Computer Networks, Vol. 50, No. 17, pp. 3434-3448, 2006.

[22] J. Na, D. Soroker, and C.-k. Kim, "Greedy Geographic Routing using Dynamic Potential Field for Wireless Ad Hoc Networks," IEEE Communication Letters., Vol. 11, No. 3, pp. 243-245, 2007.

[23] Y.-J. Kim, R. Govindan, B. Karp, and S. Shenker, "On the pitfalls of geographic face routing," Proceeding joint workshop on Foundations of mobile computing - DIALM-POMC, pp. 34-43, Cologne, Germany, 2005.

[24] F. Kuhn, R. Wattenhofer, and A. Zollinger, "Asymptotically optimal geometric mobile ad-hoc routing," Proceeding 6th international workshop on Discrete algorithms and methods for mobile computing and communications - DIALM, pp. 24-33, Atlanta, Georgia, USA, 2002.

[25] F. Kuhn, R. Wattenhoffer, and A. Zollinger, "Worst-case optimal and average-case efficient geometric ad-hoc routing," in Proc. 4th ACM international symposium on Mobile ad hoc networking \& computing,ser. MobiHoc, ACM, pp. 267-278, Annapolis, Maryland, USA, 2003

[26] F. Kuhn, R.Wattenhofer, Y. Zhang, and A. Zollinger, "Geometric adhoc routing: Of theory and practice", In Proceedings of the 22nd ACM International Symposium on the Principles of Distributed Computing(PODC), pages 63-72, Boston, Massachusetts, USA, 2003

[27] B. Leong, S. Mitra, and B. Liskov, "Path vector face routing: geographic routing with local face information," 13th IEEE International Conference on Routing Protocols, pp. 12, Boston, MA, USA, 2005 


\section{SURVEY ARTICLE}

[28] Biswas, S., \& Morris, R., "Opportunistic routing in multi-hop wireless networks", ACM SIGCOMM Computer Communication Review, Vol.34, No.1, pp.69-74, 2004

[29] Zhong, Z., Wang, J., Nelakuditi, S., \& Lu, G. H., "On selection of candidates for opportunistic any path forwarding", ACM SIGMOBILE Mobile Computing and Communications Review, Vol.10, No.4, pp.1-2, 2006

[30] R. Jain, A. Puri, and R. Sengupta, "Geographical Routing Using Partial Information for Wireless Ad Hoc Networks," IEEE Personal Communications, Vol. 8, No.1, pp. 48-57, 2001

[31] Dazhi chen and Pramod k. Varshney, "A survey of void handling techniques for geographic routing in wireless networks", IEEE communications Surveys and Tutorials, Vol. 9, No.1, 2007

[32] Hugo Barbosa-Filho, et.al, "Human Mobility: Models and Applications", arXiv.org, physics, arXiv:1710.00004, 2017.

[33] Fan Bai and Ahmed He, "A Survey of Mobility Models in Wireless Adhoc Networks", 2004.

[34] M. Guenes and J. Siekermann, "CosMos - communication scenario and mobility scenario generator for mobile ad-hoc networks", in Proc 2nd Int. Worksh, MANETs Interoper, Iss. MANETII, Las Vegas, USA, 2005

[35] B. Zhou, Y.-Z. Lee, and M. Gerla, "Direction assisted geographic routing for mobile ad hoc networks," in Proceedings of MILCOM Military Communications Conference. IEEE, 2008

[36] Seungjoon Lee, Bobby Bhattacharjee, Suman Banerjee and Bo Han, "A General Framework for Efficient Geographic Routing in Wireless Networks", Computer Networks, Vol. 54, No. 5, pp. 844-861, 2010

[37] Baban A. Mahmood and D. Manivannan, "GRB: Greedy Routing Protocol with Backtracking for Mobile Ad Hoc Networks", IEEE 12th International Conference on Mobile Ad Hoc and Sensor Systems, Dallas, TX, USA, 2015

[38] Dong Yang, Hongxing Xia, Erfei Xu, Dongliang Jing and Hailin Zhang, "An Energy-Balanced Geographic Routing Algorithm for Mobile Ad Hoc Networks" Energies, Vol. 11, No. 9, pp. 1-16, 2018

[39] Noureddine, H., Ni, Q., Min, G., \& Al-Raweshidy, H, "A New Link Lifetime Prediction Method for Greedy and Contention-based Routing in Mobile Ad Hoc Networks", 10th IEEE International Conference on Computer and Information Technology, 2010

[40] Nallusamy, C., \& Sabari, A, "Particle Swarm Based Resource Optimized Geographic Routing for Improved Network Lifetime in MANET", Mobile Networks and Applications, 2017

[41] Chih-Lin Hu and Chuluuntulga Sosorburam, "Enhanced Geographic Routing with Two-Hop Neighborhood Information in Sparse MANETs" Wireless Personal Communications: An International Journal, Vol.107, No. 1, pp. 417-436, 2019

[42] Jung, W.-S., Yim, J., \& Ko, Y.-B, "QGeo: Q-Learning-Based Geographic Ad Hoc Routing Protocol for Unmanned Robotic Networks", IEEE Communications Letters, Vol. 21, No. 10, pp. 2258-2261, 2017

[43] Haesu Hwang, In HUT, and Hyunseung Choo, "GOAFR Plus-ABC: Geographic Routing Based on Adaptive Boundary Circle in MANETs", International Conference on Information Networking, Chiang Mai, Thailand, 2009

[44] Ben Newton, Jay Aikat, Kevin Jeffay, "Geographic Routing in Large-Scale Highly-Dynamic Mobile Ad hoc Networks", IEEE 24th International Symposium on Modeling, Analysis and Simulation of Computer and Telecommunication Systems (MASCOTS), London, UK, 2015

[45] Alshehri, A., Badawy, A.-H. A., \& Huang, H, "FQ-AGO: Fuzzy Logic Q-Learning Based Asymmetric Link Aware and Geographic Opportunistic Routing Scheme for MANETs", Electronics, Vol. 9, No. 4, 2020

[46] Daeho Kanga, Hyung-Sin Kimb, Changhee Jooc, Saewoong Bahk, "ORGMA: Reliable opportunistic routing with gradient forwarding for MANETs", Computer Networks, 2017

[47] Li, N., Martinez-Ortega, J.-F., \& Diaz, V. H, "Cross-Layer and Reliable Opportunistic Routing Algorithm for Mobile Ad Hoc
Networks", IEEE Sensors Journal, Vol. 18, No. 13, pp. 5595-5609, 2018

[48] Wang, Z., Chen, Y., \& Li, C. "CORMAN: A novel cooperative opportunistic routing scheme in mobile ad hoc networks. IEEE Journal on Selected Areas in Communications, Vol.30, No.2, pp. 289-296, 2012

[49] Armir Bujari, Carlos T Calafate, Juan-Carlos Cano, Pietro Manzoni, Claudio Enrico Palazzi and Daniele Ronzani, "Flying ad-hoc network application scenarios and mobility models", International Journal of Distributed Sensor Networks, Vol 13, No.10, 2017.

[50] Samira Hayat, Evşen Yanmaz, Raheeb Muzaffar,"Survey on Unmanned Aerial Vehicle Networks for Civil Applications: A Communications Viewpoint", IEEE Communications Surveys \& Tutorials, Vol: 18, No: 4, pp 2624 - 2661, 2016.

[51] Oubbati, Omar Sami, Abderrahmane Lakas, Fen Zhou, Mesut Güneş, and Mohamed Bachir Yagoubi, "A survey on position-based routing protocols for Flying Ad hoc Networks (FANETs)", Vehicular Communications, Vol. 10, pp. 29-56, 2017.

[52] Guillen-Perez, A. and Cano, M.D, "Flying ad hoc networks: A new domain for network communications", Sensors, Vol.18, No.10, p.3571, 2018

[53] Omar Sami Oubbatia, , Abderrahmane Lakasb, Fen Zhouc, Mesut G"unessd, Nasreddine Lagraaa, Mohamed Bachir Yagoubia, "Intelligent UAV-Assisted Routing Protocol for Urban VANETs", Computer Networks, 2017

[54] Robert L. Lidowski, Barry E. Mullins, Rusty O. Baldwin, "A novel communications protocol using geographic routing for swarming UAVs performing a Search Mission", In Proceedings of the 2009 IEEE International Conference on Pervasive Computing and Communications, USA, 2009.

[55] Vieira, L. F. M., \& Cunha, A. V. dos S, "Performance of Greedy Forwarding in Geographic Routing for the Internet of Drones", Internet Technology Letters, Vol: 1, No:5, 2018.

[56] Qamar Usman, Omer Chughtai, Nadia Nawaz, Zeeshan Kaleem, Kishwer Abdul Khaliq, Long D. Nguyen, "A Reliable Link-adaptive Position-based Routing Protocol for Flying Ad hoc Network", Mobile Networks and Applications, 2021.DOI:https://doi.org/10.1007/s11036-021-01758-w

[57] Lin Lin, Qibo Sun, Jinglin Li, Fangchun Yang, "A Novel Geographic Position Mobility Oriented Routing Strategy for UAVs", Journal of Computational Information Systems, Vol:8, No: 2, pp 709-716, 2012.

[58] E. Kuiper, S. Nadjm-Tehrani, "Geographical routing with location service in intermittently connected MANETs", IEEE Transactions on Vehicular Technology, Vol. 60 , No.2, pp. 592-604, 2011.

[59] Jabbar, J. P. Sterbenz, "AeroRP: A geolocation assisted aeronautical routing protocol for highly dynamic telemetry environments", in: Proceedings of the International Telemetering Conference, pp. 1-10, Las Vegas, NV, 2009.

[60] D. Ros ario, Z. Zhao, T. Braun, E. Cerqueira, A. Santos, I. Alyafawi, "Opportunistic routing for multi-flow video dissemination over flying ad-hoc networks", in: Proceedings of the 15th International IEEE Symposium on a World of Wireless, Mobile and Multimedia Networks (WoWMoM), pp. 1-6, Sydney, NSW, Australia, 2014

[61] Arafat, M. Y., \& Moh, S, "Location-Aided Delay Tolerant Routing Protocol in UAV Networks for Post-Disaster Operation", IEEE Access, 2018

[62] Xiong Wang, Luoyi Fu, Yang Zhang, Xiaoying Gan and Xinbing Wang, "VDNet: an infrastructure-less UAV-assisted sparse VANET system with vehicle location prediction", Wireless Communications and Mobile Computing, 2016

[63] Omar Sami Oubbati, Abderrahmane Lakas †, Nasreddine Lagraa, and Mohamed Bachir Yagoubi, "CRUV: Connectivity-based Traffic Density Aware Routing using UAVs for VANets", International Conference on Connected Vehicles and Expo (ICCVE), 2015

[64] Xiaoyan Ma, Simona Chisiu , Rahim Kacimi and Riadh Dhaou, "Opportunistic Communications in WSN Using UAV", 14th IEEE 


\section{SURVEY ARTICLE}

Annual Consumer Communications \& Networking Conference (CCNC), USA, 2017

[65] He, Y., Tang, X., Zhang, R., Du, X., Zhou, D., \& Guizani, M, “A Course-Aware Opportunistic Routing Protocol for FANETs". IEEE Access, Vol. 7, pp. 144303-144312, 2019

[66] Stefano Basagni, Alessio Carosi, and Chiara Petriol, "Mobility in Wireless Sensor Networks", Technical Report, 2012, https://www2.eecs.berkeley.edu/Pubs/TechRpts/2012/EECS-2012270.pdf

[67] Ricardo Silva, JorgeSa Silva, Fernando Boavida, "Mobility in wireless sensor networks - Survey and proposal", Computer Communications, Vol 52, pp 1-20, 2014.

[68] R. Shah, S. Roy, S. Jain, and W. Brunette, "Data mules: modeling a three-tier architecture for sparse sensor networks," in Proceedings of the First IEEE International Workshop on Sensor Network Protocols and Applications, pp. 30-41, Anchorage, AK, USA, 2003

[69] P. Juang, H. Oki, Y. Wang, M. Martonosi, L. S. Peh, and D. Rubenstein, "Energy-efficient computing for wildlife tracking: design tradeoffs and early experiences with zebranet," ACM SIGOPS Operation System Review, Vol. 36, No. 5, pp. 96-107, 2002.

[70] B. Hull, V. Bychkovsky, Y. Zhang, K. Chen, M. Goraczko, A. Miu, E. Shih, H. Balakrishnan, and S. Madden, "Cartel: a distributed mobile sensor computing system," in Proceedings of ACM the 4th international conference on Embedded networked sensor systems, SenSys, pp. 125-138, Boulder, Colorado, 2006.

[71] H. Smeets, C.-Y. Shih, M. Zuniga, T. Hagemeier, and P. Marron, "Trainsense: A novel infrastructure to support mobility in wireless sensor networks," Lecture Notes in Computer Science, Vol. 7772, pp. 18-33, 2013.

[72] T. Zhang, D. Wang, J. Cao, Y. Q. Ni, L.-J. Chen, and D. Chen, "Elevator-assisted sensor data collection for structural health monitoring," IEEE Transactions on Mobile Computing, Vol. 11, No. 10, pp. 1555-1568, 2012.

[73] D. Johnson, T. Stack, R. Fish, D. Flickinger, L. Stoller, R. Ricci, and J. Lepreau, "Mobile emulab: A robotic wireless and sensor network testbed," in Proceedings of IEEE the 25th IEEE International Conference on Computer Communications (INFOCOM), pp. 1-12, Barcelona, Spain, 2006.

[74] P. De, A. Raniwala, R. Krishnan, K. Tatavarthi, J. Modi, N. A. Syed, S. Sharma, and T.-c. Chiueh, "Mint-m: an autonomous mobile wireless experimentation platform," in Proceedings of the 4th international conference on Mobile systems, applications and services, ser. MobiSys, pp. 124-137, Uppsala, Sweden, 2006

[75] S. Gandham, M. Dawande, R. Prakash, and S. Venkatesan, "Energy efficient schemes for wireless sensor networks with multiple mobile base stations," in Proc. of IEEE Global Telecommunications Conference, Vol. 1, pp. 377-381, San Francisco, USA, 2003.

[76] F. Ye, H. Luo, J. Cheng, S. Lu, and L. Zhang, "A two-tier data dissemination model for large-scale wireless sensor networks," in Proceedings of ACM the 8th annual international conference on Mobile computing and networking, ser. MobiCom, pp. 148-15, Atlanta, Georgia, USA, 2002

[77] C.-J. Lin, P.-L. Chou, and C.-F. Chou, "Hcdd: hierarchical clusterbased data dissemination in wireless sensor networks with mobile sink," in Proceedings of the ACM 2006 international conference on Wireless communications and mobile computing, ser. IWCMC, pp. 1189-1194, Vancouver, British Columbia, Canada, 2006.

[78] D. Jea, A. Somasundara, and M. Srivastava, "Multiple controlled mobile elements (data mules) for data collection in sensor networks," Lecture Notes in Computer Science, Vol. 3560, pp. 244-257, 2005.

[79] S. Basagni, A. Carosi, E. Melachrinoudis, C. Petrioli, and Z. M. Wang, "Controlled sink mobility for prolonging wireless sensor networks lifetime," Wireless Networks, Vol. 14, No. 6, pp. 831-858, 2008.

[80] Y. Shi and Y. Hou, "Theoretical results on base station movement problem for sensor network," in INFOCOM 2008. The 27th
Conference on Computer Communications. IEEE, pp. 1-5, Phoenix, AZ, USA, 2008

[81] M. Ma and Y. Yang, "Sencar: An energy-efficient data gathering mechanism for large-scale multihop sensor networks," IEEE Transactions on Parallel and Distributed Systems, Vol. 18, No. 10, pp. 1476-1488, 2007.

[82] G. Xing, T. Wang, Z. Xie, and W. Jia, "Rendezvous planning in mobility-assisted wireless sensor networks," in Proceedings of the 28th IEEE International Real-Time Systems Symposium (RTSS), pp. 311-320, Tucson, Arizona, USA, 2007

[83] M. Zhao and Y. Yang, "Bounded relay hop mobile data gathering in wireless sensor networks," IEEE Transactions on Computers, Vol. 61, No. 2, pp. 265-277, 2012.

[84] Khelifi, M., Bourouais, S., Lounis, O., \& Moussaoui, S, "GRCS: A cluster-based geographic routing protocol for WSNs", Ninth International Conference on Ubiquitous and Future Networks (ICUFN), 2017

[85] Yu, F., Park, S., Lee, E., \& Kim, S.-H. "Elastic routing: a novel geographic routing for mobile sinks in wireless sensor networks", IET Communications, Vol. 4, No. 6, pp. 716-727, 2010

[86] Tran Dinh Hieu, Le The Dung, and Byung-Seo Kim, "StabilityAware Geographic Routing in Energy Harvesting Wireless Sensor Networks", Sensors, 2016

[87] Mouna Rekik, Nathalie Mitton, Zied Chtourou, "GRACO: a geographic GReedy routing with an ACO-based void handling technique" International Journal of Sensor Networks, Vol.26, No.3, pp. $145-161,2018$

[88] Sun, Y., Guo, J., \& Yuhui Yao, "Speed Up-Greedy Perimeter Stateless Routing Protocol for Wireless Sensor Networks (SUGPSR)", IEEE 18th International Conference on High Performance Switching and Routing (HPSR), 2017

[89] Basagni, S., Carosi, A., Melachrinoudis, E., Petrioli, C., \& Wang, Z, "A New MILP Formulation and Distributed Protocols for Wireless Sensor Networks Lifetime Maximization", IEEE International Conference on Communications, 2006

[90] Antonio Caruso, Francesco Paparella, Luiz F. M. Vieira, Melike Erol, Mario Gerla, "The Meandering Current Mobility Model and its Impact on Underwater Mobile Sensor Networks", IEEE INFOCOM The 27th Conference on Computer Communications, pp. 771-779, Phoenix, AZ, USA, 2008

[91] zheng yang and yunhao liu, "Sea Depth Measurement with Restricted Floating Sensors", 28th IEEE International Real-Time Systems Symposium (RTSS), Tucson, AZ, USA 2013

[92] Xie, P., Cui, J. and Lao, L, "VBF: Vector-based forwarding protocol for underwater sensor networks", IFIP International Federation for Information Processing, pp. 1216-1221, 2006.

[93] Nicolaou, N., See, A., Xie, P., Cui, J. H. and Maggiorini, D, "Improving the Robustness of Location-Based Routing for Underwater Sensor Networks," IEEE Oceans Conference, pp.1-6, Aberdeen, UK, 2007.

[94] Jinming, C., Xiaobing, W. and Guihai, C. (2008) "REBAR: a reliable and energy balanced routing algorithm for UWSNs". In Proceedings of the seventh international conference on grid and cooperative computing, pp. 349-355, Shenzhen, China 2008

[95] Daeyoup, H. and Dongkyun, K., "DFR: Directional flooding-based routing protocol for underwater sensor networks" IEEE OCEANS, pp. 1-7, Quebec City, QC, Canada, 2008

[96] Anupama, KR., Sasidharan, A. and Vadlamani, S., "A location-based clustering algorithm for data gathering in 3D underwater wireless sensor networks" In Proceedings of the International Symposium on Telecommunications, IST, pp. 343-348, Tehran, Iran, 2008

[97] Rahman Z, Hashim F, Rasid MFA, Othman M, "Totally opportunistic routing algorithm (TORA) for underwater wireless sensor network". PLoS ONE, Vol. 13, No. 6, pp. 1-28, 2018

[98] Chirdchoo, N., Wee-Seng, S. and Kee Chaing, C, "Sector-based routing with destination location prediction for underwater mobile networks", In Proceedings of the international conference on 


\section{SURVEY ARTICLE}

advanced information networking and applications workshops, pp. 1148-1153, Bradford, UK, 2009.

[99] Coutinho, R. W. L., Vieira, L. F. M., \& Loureiro, A. A. F, "DCR: Depth-Controlled Routing protocol for underwater sensor networks", IEEE Symposium on Computers and Communications (ISCC), 2013

[100] Seyed Mohammad Ghoreyshi, Alireza Shahrabi, and Tuleen Boutaleb, "A Stateless Opportunistic Routing Protocol for Underwater Sensor Networks", Wireless Communications andMobileComputingVolume, pp. 1-18, 2018

[101] Noh, Y., Lee, U., Wang, P., Choi, B. S. C., \& Gerla, M, "VAPR: Void-Aware Pressure Routing for Underwater Sensor Networks", IEEE Transactions on Mobile Computing, Vol. 12, No. 5, pp. 895908, 2013

[102] Coutinho, R. W. L., Boukerche, A., Vieira, L. F. M., \& Loureiro, A. A. F, "GEDAR: Geographic and opportunistic routing protocol with Depth Adjustment for mobile underwater sensor networks", IEEE International Conference on Communications (ICC), 2014

[103] Choffnes, D., Bustamante, F, "An Integrated Mobility and Traffic Model for Vehicular Wireless Networks", In: 2nd ACM Workshop on Vehicular Ad Hoc Networks, pp. 69-78, Cologne, Germany 2005

[104] Uchiyama, A, "Mobile Ad-hoc Network Simulator based on Realistic Behavior Model", Demo Session in MobiHoc, 2005

[105] Gainaru, A., Dobre, C., Cristea, V, "A Realistic Mobility Model Based on Social Networks for the Simulation of VANETs", In: IEEE 69th Vehicular Technology Conference, pp. 1-5, Barcelona, Spain, 2009

[106] Choffnes, David, and Fabin E. Bustamante, "STRAW-An Integrated Mobility and Traffic Model for VANET", Proc. of the 10th International Command and Control Research and Technology Symposium (CCRTS), pp. 1-7, 2005.

[107] Khokhar, Rashid Hafeez, et al, "Fuzzy-assisted social-based routing for urban vehicular environments", EURASIP Journal on Wireless Communications and Networking, pp. 1-15, 2011

[108] Zhao, Jing, and Guohong Cao. "VADD: Vehicle-assisted data delivery in vehicular ad hoc networks." IEEE transactions on vehicular technology, Vol.57, No.3, pp.1910-1922, 2008.

[109] Xue, G., Luo, Y., Yu, J., \& Li, M. "A novel vehicular location prediction based on mobility patterns for routing in urban VANET", EURASIP Journal on Wireless Communications and Networking, Vol. 1, pp.1-14, 2012

[110] Lochert, C., Hartenstein, H., Tian, J., Fussler, H., Hermann, D., \& Mauve, M. "A routing strategy for vehicular ad hoc networks in city environments", IEEE Intelligent vehicles symposium, pp. 156-161, Columbus, OH, USA, 2003

[111] Seet, Boon-Chong, Genping Liu, Bu-Sung Lee, Chuan-Heng Foh, Kai-Juan Wong, and Keok-Kee Lee, "A-STAR: A mobile ad hoc routing strategy for metropolis vehicular communications", In International Conference on Research in Networking, pp. 989-999, 2004.

[112] Jerbi, M., Meraihi, R., Senouci, S. M., \& Ghamri-Doudane, Y, "Gytar: Improved greedy traffic aware routing protocol for vehicular ad hoc networks in city environments", ACM Proceedings of the 3rd international workshop on vehicular ad hoc networks, pp. 88-89, Los Angeles, CA, USA, 2006.

[113] V. Naumov and T.R. Gross. "Connectivity-aware routing (car) in vehicular ad-hoc networks", In Proceedings of the IEEE International Conference on Computer Communications, pp.1919-1927, Barcelona, Spain, 2007.

[114] Schnaufer, S., \& Effelsberg, W, "Position-based unicast routing for city scenarios", International Symposium on a World of Wireless, Mobile and Multimedia Networks, 2008

[115] B. Kirsch, W. Effelsberg, "Implementation of a Distance-VectorBased Recovery Strategy for Position-Based-Routing", Department of Mathematics and Computer Science, University of Mannheim, 2007

[116] Tsiachris, S., Koltsidas, G., \& Pavlidou, F.-N, "Junction-Based Geographic Routing Algorithm for Vehicular Ad hoc Networks",
Wireless Personal Communications, Vol. 71, No. 2, pp., 955-973, 2012

[117] Wang, L., Chen, Z., \& Wu, J, “An Opportunistic Routing for Data Forwarding Based on Vehicle Mobility Association in Vehicular Ad Hoc Networks", Information, Vol. 8, No. 4, 2017

[118] I. Leontiadis and C. Mascolo, "GeOpps: geographical opportunistic routing for vehicular networks," in Proceedings of the IEEE International Symposium on a World of Wireless, Mobile and Multimedia Networks (WOWMOM), pp. 1-6, Espoo, Finland, 2007.

[119] Ghaffari, A, "Hybrid opportunistic and position-based routing protocol in vehicular ad hoc networks", Journal of Ambient Intelligence and Humanized Computing, 2019

[120] Lee, K. C., Le, M., Harri, J., \& Gerla, M. "Louvre: Landmark overlays for urban vehicular routing environments", IEEE Conference on Vehicular Technology, Calgary, BC, Canada, 2008.

[121] Barootkar M, Ghaffarpour Rahbar. A, \& Sabaei, M, "LDAOR Location and Direction Aware Opportunistic Routing in Vehicular Ad hoc Networks", Journal of Telecommunications and Information Technology, Vol. 1, No. 1, pp 68-83, 2016

[122] Sadatpour, V., Zargari, F., \& Ghanbari, M, "A Collision Aware Opportunistic Routing Protocol for VANETs in Highways", Wireless Personal Communications, 2019

[123] Li, N., Martinez-Ortega, J.-F., Diaz, V. H., \& Fernandez, J. A. S, "Probability Prediction-Based Reliable and Efficient Opportunistic Routing Algorithm for VANETs", IEEE/ACM Transactions on Networking, Vol. 26, No. 4, pp. 1933-1947, 2018

[124] Naderi, M., Zargari, F., Sadatpour, V., \& Ghanbari, M, "A 3Parameter Routing Cost Function for Improving Opportunistic Routing Performance in VANETs", Wireless Personal Communications, Vol. 97, No. 1, pp. 109-123, 2017

[125] Uddin, Md Yusuf S., David M. Nicol, Tarek F. Abdelzaher, and Robin H. Kravets, "A post-disaster mobility model for delay tolerant networking", In Winter Simulation Conference, pp. 2785-2796, Austin, TX, USA, 2009.

[126] Walker, Brenton D., T. Charles Clancy, and Joel K. Glenn, "Using localized random walks to model delay-tolerant networks", In Military Communications Conference, MILCOM IEEE, pp. 1-7, San Diego, CA, USA, 2008

[127] M Shahzamal, M F Pervez, M A U Zaman, and M D Hossain, "Mobility Models for Delay Tolerant Network: A Survey", International Journal of Wireless \& Mobile Networks, Vol. 6, No. 4, 2014.

[128] F. Ekman, A. Ker"anen, J. Karvo, and J. Ott, "Working day movement model", in Proceedings of the In Proceedings of the $1^{\text {st }}$ ACMSIGMOBILE workshop onMobilitymodels, (MobilityModels), pp. 33-40, Hong Kong, China, 2008.

[129] Q. Zheng, X. Hong, J. Liu, D. Cordes, and W. Huang, "Agenda driven mobility modelling", International Journal of Ad Hoc and Ubiquitous Computing, Vol. 5, No. 1, pp. 22-36, 2009.

[130] X. Zhu, Y. Bai, W. Yang, Y. Peng, and C. Bi, "SAME: A students' daily activity mobility model for campus delay-tolerant networks," in Proceedings of the 8th Asia-Pacific Conference on Communications (APCC), pp. 528-533, Jeju Island, South Korea, 2012.

[131] J. Ghosh, S. J. Philip, and C. Qiao, "Sociological orbit aware location approximation and routing (SOLAR) in MANET", Ad Hoc Networks, Vol. 5, No. 2, pp. 189-209, 2007.

[132] W. J. Hsu, T. Spyropoulos, K. Psounis, and A. Helmy, "Modeling time-variant user mobility in wireless mobile networks," in Proceedings of the 26th IEEE International Conference on Computer Communications, pp. 758-766, Barcelona, Spain, 2007.

[133] K. Lee, S. Hong, S. J. Kim, I. Rhee, and S. Chong, "Slaw: A new mobility model for human walks", in Proceedings of the INFOCOM, IEEE, pp. 855-863, Rio de Janeiro, Brazil, 2009.

[134] C. Boldrini and A. Passarella, "HCMM, Modelling spatial and temporal properties of human mobility driven by users social relationships," Computer Communications, Vol. 33, No. 9, pp. 10561074,2010 


\section{SURVEY ARTICLE}

[135] N. Vastardis and K. Yang, "An enhanced community-based mobility model for distributed mobile social networks," Journal of Ambient Intelligence and Humanized Computing, Vol. 5, No. 1, pp. 65-75, 2014.

[136] V. Borrel, F. Legendre, M. D. de Amorim, and S. Fdida, "Simps, Using sociology for personal mobility," IEEE/ACMTransactions on Networking, Vol. 17, No. 3, pp. 831-842, 2009.

[137] D. Fischer, K.Herrmann, andK. Rothermel, "GeSoMo-A general social mobility model for delay tolerant networks," in Proceedings of the 7th International Conference on Mobile Adhoc and Sensor Systems (MASS), IEEE, pp. 99-108, San Francisco, CA, USA, 2010.

[138] Dávid Hrablák, Martin Matis, L’ubomír Doboš, and Ján Papaj, "Students Social Based Mobility Model for MANET-DTN Networks", Mobile Information System, pp. 1-13, 2017

[139] H. Kang and D. Kim, "Vector routing for delay tolerant networks," in Proceedings of the 68th IEEE Vehicular Technology Conference (VTC-Fall), pp. 1-5, Calgary, Canada, 2008.

[140] Yue Cao; Zhili Sun ; Ning Wang; Haitham Cruickshank ; Naveed Ahmad, "A Reliable and Efficient Geographic Routing Scheme for Delay/Disruption Tolerant Networks", IEEE Wireless Communications Letters, Vol. 2 , No. 6, pp. 603-606, 2013

[141] H. Kang and D. Kim, "HVR: history-based vector routing for delay tolerant networks," in Proceedings of the 18th Internatonal Conference on Computer Communications and Networks (ICCCN), pp. 1-6, San Francisco, Calif, USA, 2009.

[142] Y. Cao, Z. Sun, N. Wang, M. Riaz, H. Cruickshank, and X. Liu, "Geographic-based spray-and-relay (GSaR): an efficient routing scheme for DTNs," IEEE Transactions on Vehicular Technology, Vol. 64, No. 4, pp. 1548-1564, 2015

[143] Yue Cao, Kaimin Wei, Geyong Min, Jian Weng, Xin Yang and Zhili Sun, "A Geographic Multi-Copy Routing Scheme for DTNs With Heterogeneous Mobility", IEEE Systems Journal, Vol. 12, No.1, pp. 790-801, 2016

[144] O. Turkes, H. Scholten, and P. Havinga, "RoRo-LT: social routing with next-place prediction from self-assessment of spatiotemporal routines," in Proceedings of the 10th International Conference on Ubiquitous Intelligence and Computing and $10^{\text {th }}$ International Conference on IEEE Autonomic and Trusted Computing (UIC/ATC), pp. 201-208, Vietri sulMare, Italy, 2013

[145] V. N. G. J. Soares, J. J. P. C. Rodrigues, and F. Farahmand, "GeoSpray: a geographic routing protocol for vehicular delay tolerant networks," Information Fusion, Vol. 15, No. 1, pp. 102-113, 2014.

[146] Y. Cao, Z. Sun, H. Cruickshank, and F. Yao, "Approach-and Roam $(\mathrm{AaR})$ : a geographic routing scheme for delay/disruption tolerant networks," IEEE Transactions on Vehicular Technology, Vol. 63, No. 1, pp. 266-281, 2014

[147] Cao, Y., Han, C., Zhang, X., Kaiwartya, O., Zhuang, Y., Aslam, N., Dianati, M, "A Trajectory-Driven Opportunistic Routing Protocol for VCPS", IEEE Transactions on Aerospace and Electronic Systems, Vol. 54, No. 6, pp. 2628-2642, 2018

[148] Yue Cao; Zhili Sun; Ning Wang; Fang Yao; Haitham Cruickshank, "Converge-and-Diverge: A Geographic Routing for Delay/Disruption-Tolerant Networks Using a Delegation Replication Approach", IEEE Transactions on Vehicular Technology, Vol. 62, No. 5, pp. 2339-2343, 2013

[149] H.-Y. Huang, P.-E. Luo, M. Li et al., "Performance evaluation of SUVnet with real-time traffic data", IEEE Transactions on Vehicular Technology, Vol. 56, No. 6, pp. 3381-3396, 2007

[150] X. Li, W. Shu, M. Li, H. Huang, and M.-Y. Wu, "DTN routing in vehicular sensor networks," in Proceedings of the IEEE Global Telecommunications Conference (GLOBECOM), pp. 752- 756, New Orleans, La, USA, 2008.

[151] J. A. B. Link, D. Schmitz, and K. Wehrle, "GeoDTN: geographic routing in disruption tolerant networks," in Proceedings of the 54th
Annual IEEE Global Telecommunications Conference (GLOBECOM), pp. 1-5, Houston, Tex, USA, 2011.

[152] Pei-Chun Cheng . Kevin C. Lee * Mario Gerla • Jérôme Härri, "GeoDTN+Nav: Geographic DTN Routing with Navigator Prediction for Urban Vehicular Environments", Mobile Networks and Applications, Vol.15, No. 1, pp. 61-82, 2010

[153] Jinyang Li, John Jannotti, Douglas S. J. De Couto, David R. Karger, Robert Morris, Robert, "A Scalable Location Service for Geographic Ad Hoc Routing", Proceedings of the Annual International Conference on Mobile Computing and Networking, 2000.

[154] S.M. Das, H. Pucha, Y.C. Hu, "Performance comparison of scalable location services for geographic ad hoc routing", Proceedings IEEE 24th Annual Joint Conference of the IEEE Computer and Communications Societies, 2005.

[155] X. Shi and K. Liu, "A contention-based beaconless geographic routing protocol for mobile ad hoc networks", Third International Conference on Communications and Networking in China, pp. 840843, Hangzhou, China, 2008

[156] G. Y. Lee and Y. Lee, "Numerical analysis of optimum timer value for time-based location registration scheme," IEEE Communication Letters., Vol. 6, No. 10, pp. 431-433, 2002.

[157] D. Son, A. Helmy, B. Krishnamachari, "The effect of mobilityinduced location errors on geographic routing in mobile ad hoc sensor networks: analysis and improvement using mobility prediction", IEEE Transactions on Mobile Computing, Vol. 3, No 3, pp.233-245, 2004

[158] Quanjun Chen, Salil S. Kanhere, Mahbub Hassan, "Adaptive Position Update for Geographic Routing in Mobile Ad-hoc Networks", IEEE Transactions on Mobile Computing, Vol 12, No 3, pp 489-501, 2013.

[159] Marco Fiore, Claudio Casetti, Carla-Fabiana Chiasserini, Panagiotis Papadimitratos, "Discovery and Verification of Neighbor Positions in Mobile Ad Hoc Networks", IEEE Transactions on Mobile Computing, Vol 12, No. 2, pp. 289-303, 2013.

[160] S.H. Shah and K. Nahrstedt. "Predictive location-based QoS routing in mobile ad hoc networks",Proceedings of IEEE International Conference on Communications, 2002.

[161] Liu, G. \& Maguire Jr., "A Class of Mobile Motion Prediction Algorithms for Wireless Mobile Computing and Communications", Mobile Networks and Applications Journal, Springer, Vol.1, No.2, pp 113-121, 1996

[162] M. Rieke, T. Foerster, A. Broering, "Unmanned aerial vehicles as mobile multi-platforms", in: The 14th AGILE International Conference on Geographic Information Science, pp.18-21, 2011.

[163] Chellapa-Doss, R., Jennings, A. \& Shenoy, N., "User Mobility Prediction in Hybrid and Ad Hoc Wireless Networks", Proceeding of the Australian Telecommunications Networks and Applications Conference (ATNAC), 2003

[164] Saman, N. \& Karmouch, A., "A Mobility Prediction Architecture Based on Contextual Knowledge and Spatial Conceptual Maps" IEEE Transactions on Mobile Computing. Vol.4, No.6, pp. 537-551, 2005

[165] Kulkarni, Vaibhav, and Benoît Garbinato. "20 Years of Mobility Modeling \& Prediction: Trends, Shortcomings \& Perspectives." In Proceedings of the 27th ACM SIGSPATIAL International Conference on Advances in Geographic Information Systems, pp. 492-495. 2019.

[166] Aarti Munjal,Tracy Camp, and Nils Aschenbruck, "Changing Trends in Modeling Mobility", Journal of Electrical and Computer Engineering, Hindwai, Vol.2012, pp. 16, 2012

[167] V. Kulkarni, A. Mahalunkar, B. Garbinato, and J. D. Kelleher. Examining the limits of predictability of human mobility. Entropy, Vol.21, No.4, pp.432, 2019

[168] J. Feng, Y. Li, C. Zhang, F. Sun, F. Meng, A. Guo, and D. Jin. Deepmove: Predicting human mobility with attentional recurrent networks. In WWW, 2018 


\section{SURVEY ARTICLE}

[169] Myounggyu Won, Wei Zhang, Chien-An Chen, Radu Stoleru, "GROLL: Geographic Routing for Low Power and Lossy IoT Networks", Internet of Things, Vol 9, 2020.

[170] Dmitrii Chemodanov, Flavio Esposito, Andrei Sukhov, Prasad Calyam, Huy Trinh, Zakariya Oraibia, "AGRA: AI-augmented geographic routing approach for IoT-based incident-supporting applications", Future Generation Computer Systems, Vol 92, pp 1051-1065, 2019.

Authors

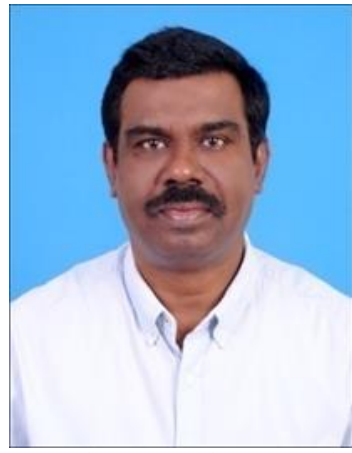

Dr. T. Sakthivel received his $\mathrm{Ph} . \mathrm{D}$. in Information Technology and Computer Science Engineering from MS University, Tirunelveli, Tamil Nadu, India in 2013. He has obtained B.E (CSE) from University of Madras and M. Tech (IT) from Punjabi University in 1995 and 2003 respectively. $\mathrm{He}$ has more than 20 years of experience in teaching, industry, and research. Currently, he is with Firstsoft Technologies (P) Ltd, Chennai, serving as a Director and focusing on cutting-edge technologies and products. His research interests mainly focus on Wireless Networks and Security, Digital Forensics, Machine Learning, Cloud Computing and IOT. He is a professional member of the ACM.

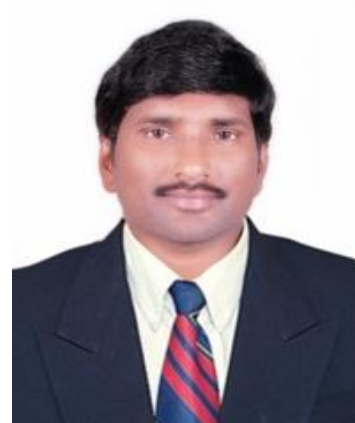

Dr. Allam Balaram, Professor, Department of Information Technology, MLR Institute of Technology, Hyderabad, Telangana State, India. He has completed his Ph.D. Computer Science and Engineering from St. Peters Institute Higher Education and Research in the year 2018 and completed M.Tech., Computer Science and Technology from Andhra University in the year 2008. His research interests include VANETs, Wireless Sensor Networks, Ad-hoc Networks and Formal Languages.

\section{How to cite this article:}

T. Sakthivel, Allam Balaram, "The Impact of Mobility Models on Geographic Routing in Multi-Hop Wireless Networks and Extensions - A Survey", International Journal of Computer Networks and Applications (IJCNA), 8(5), PP: 634-670, 2021, DOI: $10.22247 / \mathrm{ijcna} / 2021 / 209993$. 